\title{
Trigeminal Neuralgia: Current Approaches and Emerging Interventions
}

\author{
Risheng Xu \\ Michael E Xie (iD) \\ Christopher M Jackson
}

Department of Neurosurgery, Johns Hopkins University School of Medicine, Baltimore, MD, USA
Correspondence: Christopher M Jackson Johns Hopkins Hospital 1800 Orleans St., Phipps 102, Baltimore, MD, 21287, USA Email cjacks53@jhmi.edu

\begin{abstract}
Trigeminal neuralgia (TN) has been described in the literature as one of the most debilitating presentations of orofacial pain. This review summarizes over 150 years of collective clinical experience in the medical and surgical treatment of TN. Fundamentally, TN remains a clinical diagnosis that must be distinguished from other types of trigeminal neuropathic pain and/or facial pain associated with other neuralgias or headache syndromes. What is increasingly clear is that there is no catch-all medical or surgical intervention that is effective for all patients with trigeminal neuralgia, likely reflective of the fact that TN is likely a heterogenous group of disorders that jointly manifests in facial pain. The first-line treatment for TN remains anticonvulsant medical therapy. Patients who fail this have a range of surgical options available to them. In general, microvascular decompression is a safe and effective procedure with immediate and durable outcomes. Patients who are unable to tolerate general anesthesia or whose medical comorbidities preclude a suboccipital craniectomy may benefit from percutaneous methodologies including glycerol or radiofrequency ablation, or both. For patients with bleeding diathesis due to blood thinning medications who are ineligible for invasive procedures, or for those who are unwilling to undergo open surgical procedures, radiosurgery may be an excellent option-provided the patient understands that maximum pain relief will take on the order of months to achieve. Finally, peripheral neurectomies continue to provide an inexpensive and resource-sparing alternative to pain relief for patients in locations with limited economic and medical resources. Ultimately, elucidation of the molecular mechanisms underlying trigeminal neuralgia will pave the way for novel, more effective and less invasive therapies.
\end{abstract}

Keywords: trigeminal neuralgia, facial pain, glycerol, radiofrequency, microvascular decompression, partial sensory rhizotomy

\section{Introduction}

Trigeminal neuralgia (TN) has been described in the literature as one of the most debilitating presentations of orofacial pain. ${ }^{1}$ The earliest descriptions of TN date back into the seventeenth century with prominent physicians such as Johannes Fehr and Elias Schmidt, secretaries of the Imperial Leopoldina Academy of the Natural Sciences, and famous philosopher John Locke. ${ }^{2}$ Nicholas Andre first linked TN pain to the nervous system in the mid-1700s when he described the condition as a convulsive disorder thought to originate from a nerve under distress. The term tic douloureux, which Andre used to describe the clinical entity, was used to capture the facial distortions and grimaces associated with the sharp, stabbing pain that characterized the condition. In 1773, John Fothergill offered a clinical description of trigeminal neuralgia: 
"The affection seems to be peculiar to persons advancing in years, and to women more than to men. The pain comes suddenly and is excruciating; it lasts but a short time, perhaps a quarter or half a minute, and then goes off; it returns at irregular intervals, sometimes in half an hour, sometimes there are two or three repetitions in a few minutes. Eating will bring it on some persons. Talking, or the least motion of the muscles of the face affects the others; the gentlest touch of a handkerchief will sometimes bring on the pain, while a strong pressure on the part has no effect".

Although Fothergill offered an accurate clinical description of TN, he thought TN was a manifestation of some type of cancer, and proffered the term Fothergill's disorder to capture the clinical entity. ${ }^{3}$ It was not until 1820 when Dr Charles Bell localized the facial pain symptoms that patients experienced to the trigeminal ganglion that a true anatomical basis of disease was established. ${ }^{4}$

As a specific entity of facial pain, TN today is recognized by a variety of classification systems:

- International Classification of Headache Disorders (ICHD), created by the International Headache Society (IHS). ${ }^{5}$

- Classification of Chronic Pain, from the International Association for the Study of Pain (IASP). ${ }^{6}$

- International Classification of Diseases (ICD) coding, by the World Health Organization (WHO). ${ }^{7}$

- Classification from the American Association of Orofacial Pain (AAOP).

- Clinical classification of trigeminal pain by Burchiel published in $2003^{8}$ and by Cruccu et al in 2016. ${ }^{9,10}$

TN thus refers to a category of disorders affecting one or more branches of the trigeminal nerve that present with neuropathic pain. ${ }^{11,12}$ They are classified as follows:

\section{Type I Trigeminal Neuralgia}

Otherwise known as typical TN, type I TN is characterized by unilateral, severe, brief, paroxysms of sharp painful attacks in the distribution of one or more branches of the trigeminal nerve. These attacks are often described as electrical and shock-like. The pain is maximal at onset, lasts several seconds, and is triggered by nonpainful stimuli. Typical triggers include cold air, brushing teeth, chewing, or talking. Trigger zones are areas in the distribution of the affected nerve branch, close to the midline. Even light touch of these trigger zones can provoke paroxysms of pain. Between episodes of pain, there are refractory periods when previous triggers no longer produce pain. Patients may become dehydrated and experience weight loss due to avoidance of triggers. The pain may be bilateral. The Cruccu classification subdivides type I TN into idiopathic TN if no vascular compression is demonstrated on imaging, or classic TN if neurovascular compression is demonstrated.

\section{Type II Trigeminal Neuralgia}

Type II TN has continuous or near-continuous pain superimposed upon the sharp painful attacks seen in type I TN. Similar to type I, the Cruccu classification includes this syndrome into both idiopathic forms if no vascular compression is noted on imaging, or classic TN if neurovascular compression is seen.

\section{Secondary Trigeminal Neuralgia}

Secondary TN is pain experienced in a trigeminal distribution caused by neurological disease other than neurovascular compression. Broadly, these etiologies may fall into inflammatory/demyelinating disease (eg, multiple sclerosis, sarcoidosis), tumors (eg, meningioma, vestibular schwannoma, trigeminal schwannoma, epidermoid, metastasis, glioma), other vascular lesions (eg, aneurysms, arteriovenous malformations, persistent trigeminal artery), connective tissue disorders (eg, scleroderma, mixed connective tissue disease), congenital diseases, and other systemic conditions (eg, Paget's disease, acromegaly, syphilis) which may affect the trigeminal nerve.

TN should not be confused with other cranial nerve syndromes such as geniculate neuralgia versus nervus intermedius neuralgia, glossopharyngeal neuralgia, ${ }^{13-16}$ superior laryngeal neuralgia, paratrigeminal neuralgia (Raeder's syndrome), ${ }^{17-21}$ or occipital neuralgia. $^{7}$ Trigeminal neuropathy due to herpes zoster, trigeminal postherpetic neuralgia, ${ }^{22-29}$ painful post-traumatic trigeminal neuropathy, ${ }^{30-33}$ or trigeminal deafferentation pain (eg, anesthesia dolorosa) $)^{8,12,34}$ must be distinguished from TN. Pain related to the mouth such as dental pain, first bite syndrome, ${ }^{35}$ or burning mouth syndrome should be separately elucidated. ${ }^{35,36}$ Other headache syndromes which should be diagnosed separately from TN include cluster headaches ${ }^{37}$ sphenopalatine neuralgia (Sluder's neuralgia), Short Lasting Unilateral Neuralgiform Pain with Conjunctival Injection and Tearing (SUNCT), and Short Lasting Unilateral Neuralgiform Pain with Cranial Autonomic Symptoms (SUNA). ${ }^{30,38-41}$ Rare other forms 
of facial pain syndromes such as persistent idiopathic facial pain, pain of psychological origin, and central neuropathic pain should be distinguished from TN ${ }^{42-47}$ These entities are discussed elsewhere in the literature and their management are not addressed in this manuscript.

\section{Methods}

We reviewed the literature indexed in PubMed, Medline, and the National Library of Medicine, and reviewed all retrospective and prospective studies summarizing treatment strategies and outcomes for trigeminal neuralgia. Inclusion criteria included patients with type I or type II TN pain, secondary TN pain associated with tumors. Exclusion criteria include other forms of non-trigeminal facial pain as mentioned above. Literature predating the 1950s was assessed for historical treatment purposes. Prospective trials were favored over retrospective studies, and large cohorts were favored over smaller case series.

\section{Epidemiology}

The prevalence rate of TN ranges between $0.03 \%$ and $0.3 \%{ }^{48-51}$ There is a female preponderance, with a male: female ratio between 1:1.5 and 1:1.7. Classic TN is generally diagnosed in elderly population with peak incidence between 50 and 60 years. V2 and V3 are the most commonly affected branches of TN. In less than $5 \%$ of the cases is the ophthalmic (V1) branch affected in isolation. Trigeminal symptoms are present in $2-4 \%$ of the patients with multiple sclerosis, and in $1-5 \%$, it can be the presenting feature of the disease. Conversely, multiple sclerosis is detected in $2-14 \%$ of the patients with TN. ${ }^{12,14,48,52-59}$

TN is more commonly seen in adults compared with pediatric $\mathrm{TN}$, which comprises less than $1.5 \%$ of all cases. $^{60-62}$ Pediatric $\mathrm{TN}$ is more likely to be bilateral (42\%) compared with adult TN. It is associated with compression of multiple cranial nerves $(46 \%)$ as a result of congenitally abnormal vessels, vascular malformations, tumors, cysts, aneurysms, or arachnoiditis.

\section{Diagnosis and Imaging}

TN is fundamentally a clinical diagnosis, and as such, neuroimaging and laboratory tests are not mandatory to make a diagnosis. Patients with a characteristic history and a normal neurologic examination other than pain may be treated without further workup. However, modern workup of patients with TN usually includes elective imaging for all patients to exclude secondary causes of
$\mathrm{TN}$, such as inflammatory or mass lesions. As computer tomography (CT) is limited in evaluating the brain parenchyma, skull base nerves, and CSF cisterns, magnetic resonance imaging (MRI) with high-resolution sequences at the skull base is usually the modality of choice. According to a report of the Quality Standards Subcommittee of the American Academy of Neurology and the European Federation of Neurological Societies, routine head imaging identifies nonvascular, structural causes of TN in up to $15 \%$ of TN patients. ${ }^{6,10,53,58,63-67}$

\section{Treatment Strategies for TN}

First-line treatment therapies for $\mathrm{TN}$ involve medical management with anticonvulsant medications (Table 1). Patients who fail medical management due to persistent pain or unacceptable side effects have transcutaneous, percutaneous, radiotherapy, and open surgical options available to them (Figure 1). Patient selection criteria, as well as the pros and cons of each procedure option are summarized in Table 2. In general, percutaneous, radiosurgical, and open surgical therapies for $\mathrm{TN}$ are most effective in patients with type 1 TN. Patients with type 2 $\mathrm{TN}$ are more likely to have pain recurrence and a shorter pain-free interval compared with patients with type 1 TN. Patients with secondary TN (eg, tumors), should undergo treatment for the underlying pathology (eg, tumor resection and decompression) in order to achieve pain relief. In patients who are not surgical candidates, medical management of secondary TN may be offered for symptomatic control.

\section{Medical Management Historical Therapies}

Eighteenth and early nineteenth centuries saw the use of various compounds like quinine, mercury, opium, arsenic, and powder of gelsenium as treatments for TN. The use of phenytoin as the first antiepileptic medication used for TN was described by Bergouignan in 1942 and ushered in the modern TN treatment era.,

\section{First-Line Treatments}

Carbamazepine is the first-line drug of choice, with oxcarbazepine also utilized given its relatively more favorable side effect profile. It is important to keep in mind that both carbamazepine and oxcarbazepine typically do not work immediately. 
Table I Medical Therapies for the Treatment of Trigeminal Neuralgia

\begin{tabular}{|c|c|c|c|}
\hline Medication & Common Dosing & Side Effects & Monitoring \\
\hline Carbamazepine & $\begin{array}{l}50 \mathrm{mg} \text { twice a day } \\
\text { (elderly population) } \\
100 \mathrm{mg} \text { twice a day } \\
\text { (younger populations) }\end{array}$ & $\begin{array}{l}\text { HLA-B*1502 variant patients, esp. in Asian patients, have } \\
\text { increased risk of SJS/TEN } \\
\text { Drug-drug interactions, by inducing CYP3A4 }\end{array}$ & $\begin{array}{l}\text { Monitor sodium, CBC, LFTs at baseline } \\
\text { and periodically after HLA-B*1502 } \\
\text { variant screening }\end{array}$ \\
\hline Oxcarbazepine & $\begin{array}{l}150 \mathrm{mg} \text { twice a day (to } \\
\text { start) } \\
300-600 \mathrm{mg} \text { twice } \\
\text { a day (goal; max } \\
1800 \mathrm{mg} \text { per day) }\end{array}$ & $\begin{array}{l}\text { Hyponatremia } \\
\text { HLA-B* } 1502 \text { variant patients have increased risk of SJS/ } \\
\text { TEN }\end{array}$ & $\begin{array}{l}\text { Monitor sodium, HLA-B*I502 variant } \\
\text { screening }\end{array}$ \\
\hline $\begin{array}{l}\text { Phenytoin and } \\
\text { fosphenytoin }\end{array}$ & $15-20 \mathrm{mg} / \mathrm{kg}$ & $\begin{array}{l}\text { Ataxia, dysarthria, nystagmus } \\
\text { Significant incidence of recurrence of the neuralgia despite } \\
\text { continuous use }\end{array}$ & $\begin{array}{l}\text { If long-term dosing attempted, free and } \\
\text { total phenytoin levels }\end{array}$ \\
\hline Baclofen & I5-80mg per day & Sedation, hypotonia, Gl upset & NA \\
\hline Lamotrigine & I00bid & SJS/TEN, skin rash, sedation, nausea & NA \\
\hline Pimozide & 4-12 mg per day & $\begin{array}{l}\text { Extrapyramidal symptoms, QT prolongation, neuroleptic } \\
\text { malignant syndrome, hemolytic anemia, dry mouth, } \\
\text { sedation, constipation }\end{array}$ & $\begin{array}{l}\text { ECG, fasting glucose and lipids, } C B C \text {, } \\
\text { CMP, monitoring for extrapyramidal } \\
\text { symptoms }\end{array}$ \\
\hline Levetiracetam & $\begin{array}{l}3000-5000 \mathrm{mg} \text { per day } \\
\text { divided BID or TID }\end{array}$ & Agitation or worsening depression & NA \\
\hline Gabapentin & $300-1200 \mathrm{mg}$ TID & $\begin{array}{l}\text { Sedation, foggy thinking, lower extremity edema or weight } \\
\text { gain }\end{array}$ & NA \\
\hline Pregabalin & $\begin{array}{l}300-600 \mathrm{mg} \text { divided } \\
\text { BID }\end{array}$ & $\begin{array}{l}\text { Sedation, dizziness, lower extremity edema, blurry vision, } \\
\text { possible thrombocytopenia }\end{array}$ & NA \\
\hline Clonazepam & 6-8 mg per day & Sedation, ataxia, memory impairment, withdrawal & NA \\
\hline Valproate & $500-1500$ per day & $\begin{array}{l}\text { Weight gain, hair loss, nausea, hepatotoxicity, pancreatitis, } \\
\text { fetal malformations, thrombocytopenia }\end{array}$ & $\begin{array}{l}\text { Total and free valproate level, LFTs, } \\
\mathrm{CBC} \text {, ammonia }\end{array}$ \\
\hline Misoprostol & $600 \mu \mathrm{g}$ per day & Diarrhea, GI discomfort, menorrhagia & NA \\
\hline
\end{tabular}

\section{Carbamazepine}

Carbamazepine was initially shown to be effective for treating $\mathrm{TN}$ in a randomized placebo-controlled trial published in $1966 .{ }^{68}$ In the trial, doses from $100 \mathrm{mg}$ three times per day to $200 \mathrm{mg}$ four times per day were used. Patients using carbamazepine for 2 weeks had a 58\% improvement in pain when compared to a $26 \%$ improvement in the placebo group, $\mathrm{p}<0.01$. However, carbamazepine has a serious side effect profile, including hyponatremia, aplastic anemia, and liver failure. ${ }^{41,58,69-72}$ Current recommendations are to monitor sodium, complete blood count (CBC), and liver function tests (LFTs) at baseline, and periodically afterwards. Carbamazepine has also been associated with hormonal alterations, including lower thyroxine levels, elevated levels of sex hormone-binding globulin, and lower free testosterone levels in men. ${ }^{69}$ Other side-effect symptoms of the medication include drowsiness, ataxia, and nausea. In an analysis of four placebo-controlled trials of carbamazepine performed in the late 1960s, the number needed to treat was 1.7-1.8; however, this study also found the number needed to harm of 3 for adverse events and 24 for serious events. ${ }^{68,73-75}$

\section{Oxcarbazepine}

Oxcarbazepine is a structural analog of carbamazepine. However, unlike carbamazepine, which is converted to 


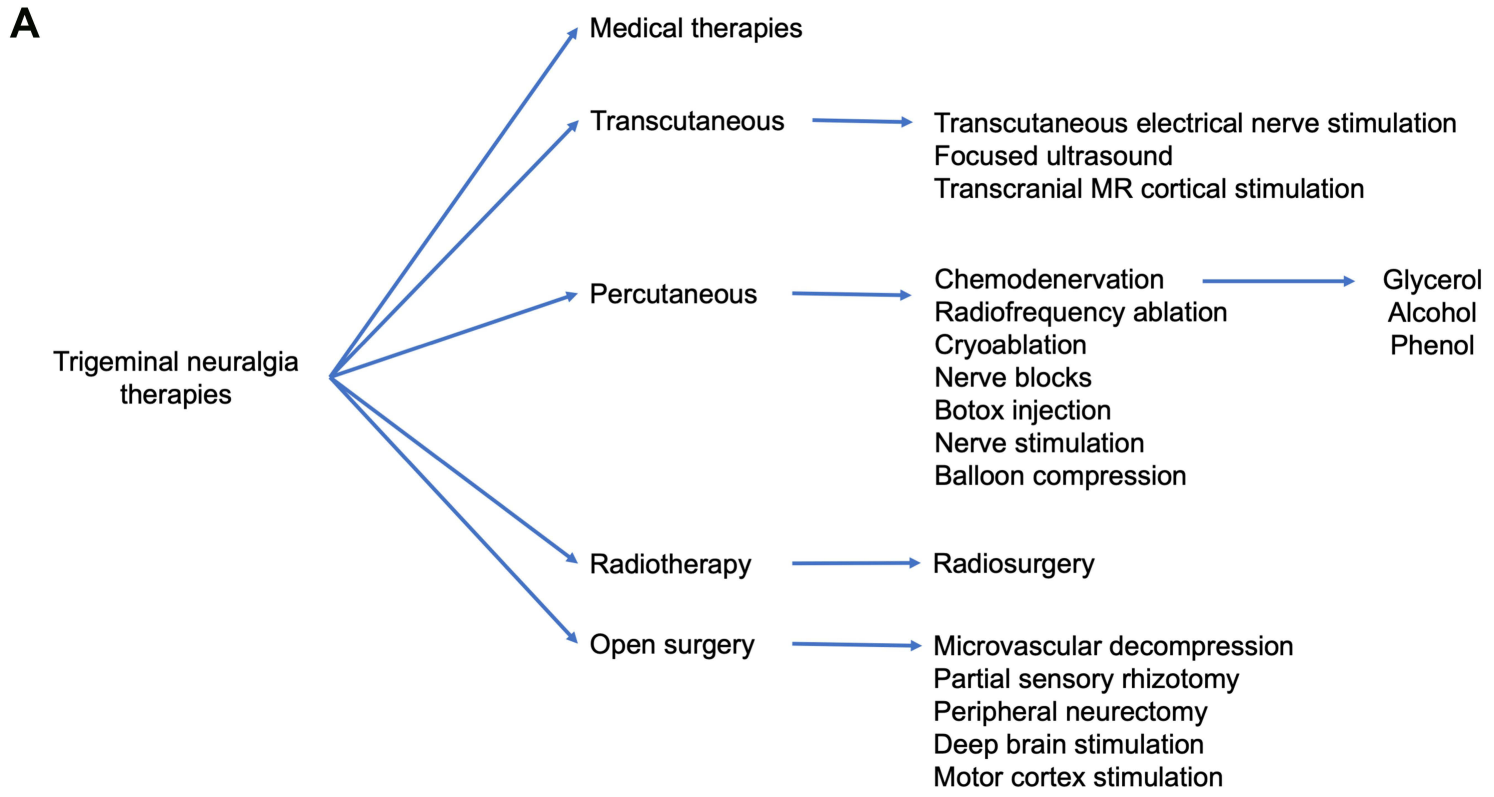

B

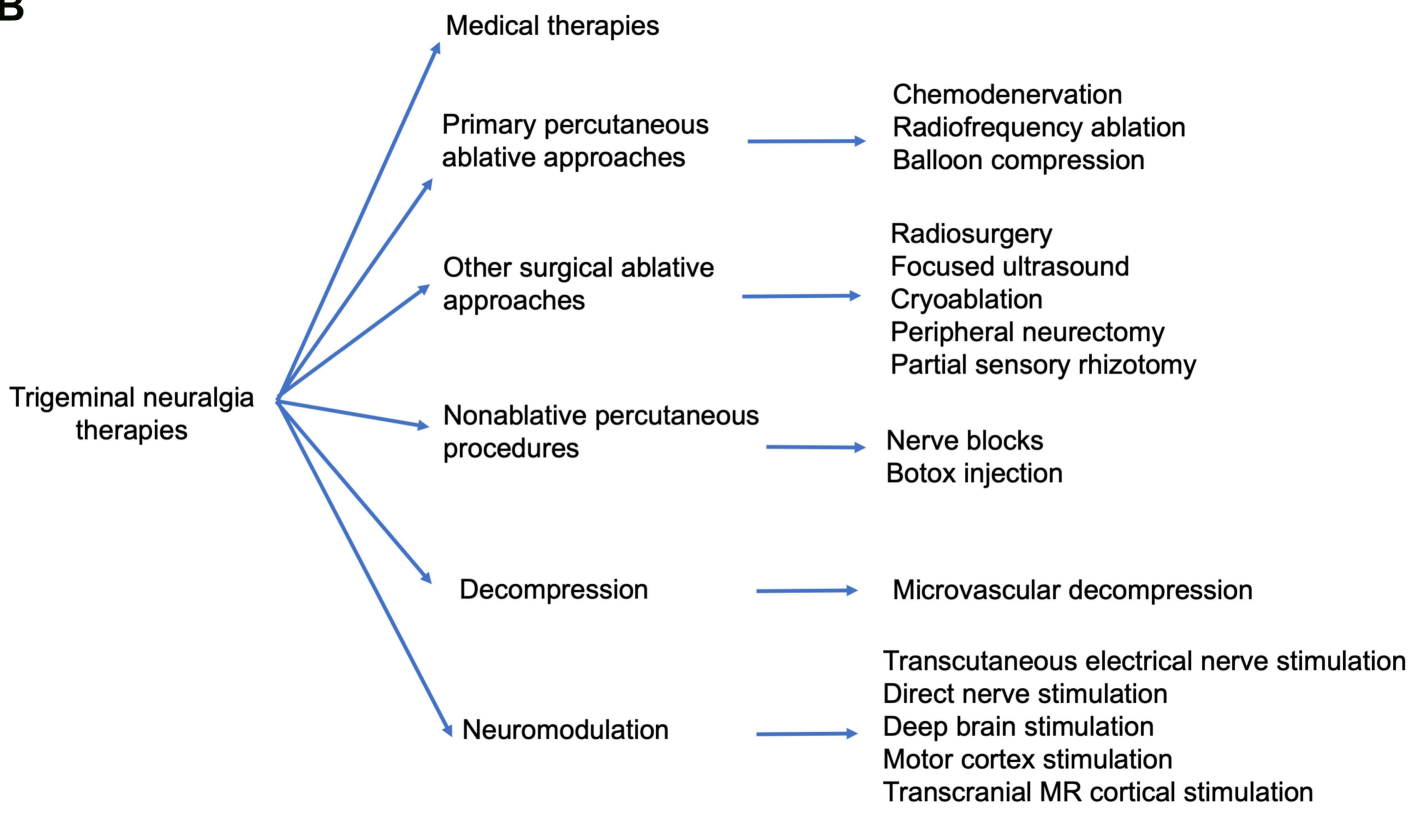

Figure I Schematic diagram of treatment modalities for trigeminal neuralgia. (A) Treatment modalities for trigeminal neuralgia grouped by operative approach. (B) Treatment modalities for trigeminal neuralgia grouped by mechanism of treatment.

an epoxide metabolite, oxcarbazepine is rapidly converted to its monohydroxy derivative (MHD), which is the main active metabolite. ${ }^{76,77}$ Although carbamazepine, oxcarbazepine, and MHD all block voltage-gated sodium channels, MHD differs from carbamazepine in that it also blocks N/P- and R-type calcium channels, whereas carbamazepine blocks L-type calcium channels. In general, oxcarbazepine is better tolerated in patients due to a more selective induction of P450 enzymes, less pharmacologic interactions with other medications, and fewer side effects. However, an important point is that hyponatremia is a serious side effect of this medication and occurs to a greater extent than with carbamazepine. As with carbamazepine, patients are at higher risk of developing SJS or TEN if they carry the HLA-B variant HLA$\mathrm{B} * 1502$. Oxcarbazepine is started at $150 \mathrm{mg}$ twice a day and can be increased to a goal of 300-600 $\mathrm{mg}$ twice a day to a maximum of $1800 \mathrm{mg}$ per day. 
Table 2 Summary of Transcutaneous, Percutaneous, Radiotherapy, and Open Surgical Treatment Options for Patients with Trigeminal Neuralgia

\begin{tabular}{|c|c|c|c|c|}
\hline & $\begin{array}{l}\text { Patient } \\
\text { Selection } \\
\text { Criteria }\end{array}$ & $\begin{array}{l}\text { Initial Pain } \\
\text { Relief Rates }\end{array}$ & Pain Recurrence & References \\
\hline \multicolumn{5}{|l|}{ Transcutaneous } \\
\hline TENS & $\begin{array}{l}\text { Retractable disease } \\
\text { without pain relief } \\
\text { after medication }\end{array}$ & $\begin{array}{l}80-90 \% \\
\text { within } 3 \\
\text { weeks }\end{array}$ & $\begin{array}{l}85 \% \text { Reduction in } \\
\text { pain after } 3 \text { months, } \\
\text { but long term } \\
\text { outcomes are not } \\
\text { well studied }\end{array}$ & {$[34,52,160,209]$} \\
\hline $\begin{array}{r}\text { Focused } \\
\text { ultrasound }\end{array}$ & $\begin{array}{l}\text { Failed standard } \\
\text { therapies, but } \\
\text { further study is } \\
\text { needed }\end{array}$ & $\begin{array}{l}\text { Further study } \\
\text { is needed }\end{array}$ & $\begin{array}{l}\text { Further study is } \\
\text { needed }\end{array}$ & {$[2|7,2| 8]$} \\
\hline $\begin{array}{l}\text { Transcranial } \\
\text { MR cortical } \\
\text { stimulation }\end{array}$ & $\begin{array}{l}\text { May be used as } \\
\text { assessment } \\
\text { method for cortical } \\
\text { stimulation }\end{array}$ & $50-60 \%$ & $\begin{array}{l}\text { Long-term studies } \\
\text { are lacking }\end{array}$ & {$[221,222]$} \\
\hline \multicolumn{5}{|l|}{ Percutaneous } \\
\hline \multicolumn{5}{|c|}{ Chemodenervation } \\
\hline Glycerol & $\begin{array}{l}\text { Failed medical } \\
\text { management }\end{array}$ & $70-90+\%$ & $\begin{array}{l}20-40 \% \text { Have pain } \\
\text { relief }\end{array}$ & $\begin{array}{l}{[126,|28,| 30,|3|,|36-138,| 43,|44,| 49, \mid 52-154,156-} \\
165,|8|, 282]\end{array}$ \\
\hline Alcohol & $\begin{array}{l}\text { Failed medical } \\
\text { management }\end{array}$ & $\begin{array}{l}80-90 \% \\
\text { success rate }\end{array}$ & $\begin{array}{l}>50 \% \text { Require } \\
\text { retreatment }\end{array}$ & {$[6,37,95,|42| 45-,|47| 5 \mid]$,} \\
\hline Phenol & $\begin{array}{l}\text { Failed medical } \\
\text { management; end- } \\
\text { stage cancer } \\
\text { patients }\end{array}$ & $80-90 \%$ & $\begin{array}{l}\sim 40 \% \text { Recurrence } \\
\text { I-2 years after } \\
\text { procedure }\end{array}$ & {$[123,148-155]$} \\
\hline $\begin{array}{l}\text { Radiofrequency } \\
\text { ablation }\end{array}$ & $\begin{array}{l}\text { Failed medical } \\
\text { management }\end{array}$ & $75-95+\%$ & $25-50 \%$ Recurrence & {$[4,|30| 43,,|68| 74-,|76| 8 \mid]$,} \\
\hline Nerve blocks & $\begin{array}{l}\text { Failed medical } \\
\text { management }\end{array}$ & $30-40 \%$ & $\begin{array}{l}\text { Pain relief may last } \\
\text { longer than } \\
\text { expected based on } \\
\text { local anesthetic's } \\
\text { duration of action, } \\
50-60 \% \text { have } \\
\text { sustained pain relief }\end{array}$ & {$[7,34,|1| 6,|17| 22,,|45-147| 49,,|5|,|76,19|-\mid 93,277]$} \\
\hline $\begin{array}{l}\text { Balloon } \\
\text { compression }\end{array}$ & $\begin{array}{l}\text { Failed medical } \\
\text { management }\end{array}$ & $80-90+\%$ & $15-50 \%$ & {$[46,|24-| 4|| 43,230]$,} \\
\hline Cryoablation & $\begin{array}{l}\text { Failed standard } \\
\text { therapy }\end{array}$ & $90+\%$ & $30-40 \%$ & {$[184,186,188]$} \\
\hline
\end{tabular}

(Continued) 
Table 2 (Continued).

\begin{tabular}{|c|c|c|c|c|}
\hline & $\begin{array}{l}\text { Patient } \\
\text { Selection } \\
\text { Criteria }\end{array}$ & $\begin{array}{l}\text { Initial Pain } \\
\text { Relief Rates }\end{array}$ & Pain Recurrence & References \\
\hline $\begin{array}{r}\text { Botox } \\
\text { injection }\end{array}$ & $\begin{array}{l}\text { Failed standard } \\
\text { therapies }\end{array}$ & $50-60 \%$ & $\begin{array}{l}50-60 \% \\
\text { Require second } \\
\text { dose at } 2 \text { months, } \\
\text { long term } \\
\text { outcomes need } \\
\text { further study }\end{array}$ & {$[63,80,83,194-205,246]$} \\
\hline $\begin{array}{c}\text { Nerve } \\
\text { stimulation }\end{array}$ & $\begin{array}{l}\text { Most commonly } \\
\text { treating Type } 2 \mathrm{TN} \\
\text { in literature }\end{array}$ & $\begin{array}{l}40-50 \% \text { but } \\
\text { sample size is } \\
\text { limited }\end{array}$ & $\begin{array}{l}\text { Long-term } \\
\text { outcomes need } \\
\text { further study }\end{array}$ & {$[2||-2 \mid 3]$} \\
\hline \multicolumn{5}{|l|}{ Radiotherapy } \\
\hline Radiosurgery & $\begin{array}{l}\text { Patients who } \\
\text { cannot tolerate } \\
\text { general anesthesia } \\
\text { or invasive } \\
\text { procedures }\end{array}$ & $\begin{array}{l}\text { Pain relief is } \\
\text { not } \\
\text { immediate; } \\
\text { maximum } \\
\text { time to pain } \\
\text { relief is } \\
\text { around I } 80 \\
\text { days after } \\
\text { treatment }\end{array}$ & $20-30 \%$ & $\begin{array}{l}{[4,7,10,38,41,54,64,71,80,120,130,135,143,175,177,223-} \\
246,274]\end{array}$ \\
\hline \multicolumn{5}{|l|}{ Open surgery } \\
\hline $\begin{array}{l}\text { Microvascular } \\
\text { decompression }\end{array}$ & $\begin{array}{l}\text { Ability to tolerate } \\
\text { general anesthesia } \\
\text { and suboccipital } \\
\text { craniectomy }\end{array}$ & $>90 \%$ & $\begin{array}{l}\sim 10 \% \\
\text { Underwent second } \\
\text { operations; most } \\
\text { recurrences within } \\
2 \text { years of surgery }\end{array}$ & $\begin{array}{l}{[4,7,|0,24,54,58,6|-63,65,66,7|, 78,80,130,| 13|,| 134-} \\
|36,| 43,|63,| 169,|17|,|74,| 75,|77,| 184,226,230,240,245,246,252- \\
265,267-272,274,275]\end{array}$ \\
\hline $\begin{array}{l}\text { Partial } \\
\text { sensory } \\
\text { rhizotomy }\end{array}$ & $\begin{array}{l}\text { Absence of } \\
\text { neurovascular } \\
\text { contact on MRI }\end{array}$ & $\begin{array}{c}80-90 \% ; \\
\text { Similar to } \\
\text { slightly worse } \\
\text { than MVD } \\
\text { patients }\end{array}$ & $\begin{array}{l}\text { Worse than MVD, } \\
47 \% \text { pain free at } 5 \\
\text { years }\end{array}$ & {$[171,177,263,269-274]$} \\
\hline $\begin{array}{l}\text { Peripheral } \\
\text { neurectomy }\end{array}$ & $\begin{array}{l}\text { Failed medical } \\
\text { therapy or severe } \\
\text { medical } \\
\text { comorbidities and } \\
\text { unable to tolerate } \\
\text { MVD suboccipital } \\
\text { craniectomy }\end{array}$ & $70-90+\%$ & $\begin{array}{l}\text { Up to } 20 \% \text {, } \\
\text { Recurrence thought } \\
\text { to be secondary to } \\
\text { peripheral nerve } \\
\text { regeneration }\end{array}$ & {$[276-281,283]$} \\
\hline $\begin{array}{l}\text { Deep brain } \\
\text { stimulation }\end{array}$ & $\begin{array}{l}\text { Refractory } \mathrm{TN} \text {, } \\
\text { excluding patients } \\
\text { with psychogenic } \\
\text { or factitious pain } \\
\text { disorders, cognitive } \\
\text { impairment, and } \\
\text { psychiatric disease }\end{array}$ & $\begin{array}{l}>90 \% \text {, but } \\
\text { sample size is } \\
\text { small }\end{array}$ & $\begin{array}{l}60 \% \text { Require } \\
\text { medication on } \\
\text { follow-up, but long } \\
\text { term outcomes are } \\
\text { not well studied }\end{array}$ & {$[34,2|4,2| 5,246]$} \\
\hline
\end{tabular}

(Continued) 
Table 2 (Continued).

\begin{tabular}{|c|l|l|l|l|}
\hline & \multicolumn{1}{|c|}{$\begin{array}{c}\text { Patient } \\
\text { Selection } \\
\text { Criteria }\end{array}$} & $\begin{array}{c}\text { Initial Pain } \\
\text { Relief Rates }\end{array}$ & Pain Recurrence & References \\
\hline $\begin{array}{c}\text { Motor cortex } \\
\text { stimulation }\end{array}$ & $\begin{array}{l}\text { rTMS may be used } \\
\text { as an initial } \\
\text { assessment for } \\
\text { cortical stimulation }\end{array}$ & $\begin{array}{c}\text { 60-80+\%, but } \\
\text { further } \\
\text { studies are } \\
\text { needed }\end{array}$ & $\begin{array}{l}>50 \%, \text { but long- } \\
\text { term outcomes are } \\
\text { poorly studied }\end{array}$ & [219-222] \\
\hline
\end{tabular}

Three randomized, double-blind controlled trials have compared oxcarbazepine to carbamazepine in TN patients. $^{71,72,77-80}$ Both reduced the number of painful attacks and global pain assessments significantly. In a study of typical TN unresponsive to carbamazepine, oxcarbazepine monotherapy provided additional pain relief in $37.1 \%$ of the patients and reduced the number of pain days by at least $50 \%$ in $67.5 \%$ of them, suggesting that oxcarbazepine can be used as a salvage therapy for patients who fail carbamazepine. 77

\section{Second-Line Treatments}

A variety of agents have been used in an attempt to treat TN. There are no double-blinded, large, randomized controlled trials for any of these agents, and published series are often nonblinded and open label.

\section{Phenytoin and Fosphenytoin}

The first successful drug for the treatment of TN was phenytoin, described by Bergouignan in $1942 . .^{81-83}$ Phenytoin works via blockade of voltage-dependent membrane sodium channels responsible for amplifying action potentials, thereby decreasing the rate of repetitive firing. Braham and Saiz, as well as Blom described the use of phenytoin in patients with TN in the early 1960 s. $^{84,85}$ They noted significant side effects of ataxia, dysarthria, nystagmus, and a significant incidence of recurrence of the neuralgia despite its continuous use. Cheshire et al evaluated the use of intravenous phenytoin or fosphenytoin for acute pain relief in the setting of an acute $\mathrm{TN}$ pain flare in three patients. ${ }^{86}$ All three patients experienced pain relief within a few hours, but its effect only lasted 1-2 days. As a result, IV phenytoin or fosphenytoin may be used as a bridging therapy for more sustained treatment options (eg, microvascular decompression). ${ }^{86}$ All three patients experienced pain relief within a few hours, but its effect only lasted 1-2 days. As a result, IV phenytoin or fosphenytoin may be used as a bridging therapy for more sustained treatment options (eg, microvascular decompression). ${ }^{87,88}$

\section{Baclofen}

Baclofen is an agonist at the beta subunit of the $\gamma$ aminobutyric acid receptor on mono and polysynaptic neurons at the spinal cord level and brain. ${ }^{89}$ Fromm et al showed that baclofen reduced the number of daily spasms in a double-blinded crossover trial of 10 patients. Baclofen is an agonist at the beta subunit of the $\gamma$-aminobutyric acid receptor on mono and polysynaptic neurons at the spinal cord level and brain. ${ }^{89}$ Fromm et al showed that baclofen reduced the number of daily spasms in a double-blinded crossover trial of 10 patients. $^{90-92}$ Seven patients had a reduction in the number of spasms per day, with a statistically significant decrease from an average of 11 spasms per day to 2.22 per day. In an expansion to an open-label trial by the same group that enrolled an additional 50 patients who were refractory to or unable to tolerate carbamazepine, $74 \%$ of the patients had a decrease in intensity and frequency of attacks at 2 weeks. Patients also did better with a combination of carbamazepine and baclofen, or baclofen and phenytoin, compared with each medication alone. ${ }^{90,92}$

\section{Lamotrigine}

Lamotrigine is an anticonvulsant that inhibits glutamate release by blocking voltage-gated sodium channels. ${ }^{76,78,80}$ It also antagonizes $\mathrm{N}$ - and $\mathrm{P} / \mathrm{Q} / \mathrm{R}$-type voltage-gated calcium channels. Zakrzewska et al demonstrated that lamotrigine was effective for the treatment of TN in a doubleblinded, placebo-controlled crossover trial containing 13 patients with disease refractory to carbamazepine, phenytoin, or a combination of the two. ${ }^{93}$ Eleven of the 13 patients showed better efficacy on lamotrigine compared to placebo, $\mathrm{p}=0.025$. In 20 patients with TN or TN associated with multiple sclerosis who were administered lamotrigine, Leandri et al found pain relief to be 
proportional to daily dosage and to drug plasma levels. ${ }^{94}$ SJS and TEN are rare but serious side effects. These reactions are most common with the initiation of the medication but can also occur at any time on lamotrigine. $^{94}$ SJS and TEN are rare but serious side effects. These reactions are most common with the initiation of the medication but can also occur at any time on lamotrigine. ${ }^{93,95}$

\section{Pimozide}

Pimozide is antipsychotic that antagonizes dopamine and serotonin receptors. Lechin et al compared pimozide to carbamazepine in a double-blind crossover trial in 48 patients. ${ }^{96}$ All patients receiving pimozide had improvement in their pain, compared with $58 \%$ of patients on carbamazepine. Overall, patients on pimozide had a $78.4 \%$ decrease in pain versus $49.7 \%$ decreased in pain on carbamazepine, $\mathrm{p}<0.001$. It is important to recognize that pimozide has significant side effects. Commonly, it can cause dry mouth, sedation, and constipation. More significant adverse effects include QT prolongation, Parkinsonism, neuroleptic malignant syndrome, and hemolytic anemia. Lechin et al noted in their trial that adverse effects of pimozide were noted in 40 (83.3\%) of 48 patients and included "physical and mental retardation, hand tremors, memory impairment, involuntary movements during sleep, and slight Parkinson's disease manifestations." Taking into consideration its significant sideeffect profile, it is unsurprising that pimozide is rarely prescribed for $\mathrm{TN}$ despite its efficacy at reducing symptoms.

\section{Levetiracetam}

Levetiracetam is an anticonvulsant that binds to SV2A, a synaptic vesicle glycoprotein, and is thought to inhibit presynaptic calcium channels and decrease neuronal excitability. ${ }^{97}$ Jorns et al studied the effects of levetiracetam in 10 patients in a 10 -week, prospective, open-label pilot study. ${ }^{98}$ At daily doses of $3000 \mathrm{mg}$ to $5000 \mathrm{mg}$ levetiracetam, 4 out of 10 patients experienced some degree of improvement. In another open-label, uncontrolled trial, Mitsikostas et al administered levetiracetam at doses of 3000 to $4000 \mathrm{mg}$ per day, added to previously partially effective medication regimens. ${ }^{99}$ Over 16 weeks, the mean daily attack frequency was reduced $62.4 \%$ from an average of 9.9 to $3.3, p<0.001$. The number of days per week that patients experienced attacks went from 6.3 to $3.5, \mathrm{p}<0.001$. Side effects of levetiracetam are rare cases of agitation or worsening depression. ${ }^{100}$

\section{Gabapentin}

Gabapentin is an anticonvulsant, which was designed to mimic the neurotransmitter GABA. ${ }^{101,102}$ However, it does not bind to GABA receptors, but rather exerts its effect through inhibition of the $\alpha 2 \delta$ subunit of voltage gated calcium channels. Debta et al found the efficacy of gabapentin alone in newly diagnosed trigeminal neuralgia patients to be $60-80 \%$, but inferior to treatment with oxcarbazepine. $^{79}$ Lemos et al showed that patients receiving gabapentin in combination with ropivacaine block had a significantly lower number of pain days than with one of the treatments alone, $\mathrm{p}=0.003 .{ }^{103}$ Cheshire et al examined 194 cases of $\mathrm{TN}$, many of whom had paroxysmal facial pain resistant to previous surgical interventions or treatment with multiple medications. ${ }^{104}$ Of the 92 who had received a trial of gabapentin, 43 (47\%) reported reduction in facial pain. The onset of pain reduction was between 1 and 3 weeks. Typical side effects of gabapentin include sedation, dizziness, and foggy thinking. Occasionally, patients can develop lower extremity edema or weight gain. ${ }^{104}$ Of the 92 who had received a trial of gabapentin, $43(47 \%)$ reported reduction in facial pain. The onset of pain reduction was between 1 and 3 weeks. Typical side effects of gabapentin include sedation, dizziness, and foggy thinking. Occasionally, patients can develop lower extremity edema or weight gain.

\section{Pregabalin}

Pregabalin is similar to gabapentin in that it is also a GABA analog that inhibits the $\alpha 2 \delta$ subunit of voltagegated calcium channels and reduces neurotransmitter release. ${ }^{105}$ Compared to gabapentin, however, pregabalin exhibits improved absorption and pharmacokinetic profiles. Hamasaki et al studied pregabalin in 33 patients with carbamazepine-refractory $\mathrm{TN}$, with $48.5 \%$ of patients reporting improved pain. ${ }^{106}$ A logistic regression analysis demonstrated that among all the clinical variables considered, older age was significantly associated with effectiveness of pregabalin treatment. Obermann et al studied 53 patients with $\mathrm{TN}$ with or without chronic facial pain and found that $39(74 \%)$ patients improved after 8 weeks. ${ }^{107}$ Patients without chronic facial pain were statistically more likely to respond, $p=0.02$. Rustagi et al demonstrated in a trial of 22 patients that uses pregabalin or lamotrigine in addition to carbamazepine had equal improvement in pain 
control; however, patients on pregabalin had fewer side effects. ${ }^{95}$ Side effects of pregabalin are similar to those of gabapentin, including sedation and dizziness, and lower extremity edema. In rare cases, patients have been seen to develop thrombocytopenia.

\section{Clonazepam}

Clonazepam is a highly potent and long-acting benzodiazepine that acts as a positive allosteric modulator on GABA-A receptors. ${ }^{71,76}$ Trialed in 30 patients that were refractory to carbamazepine in $1975,40 \%$ had complete control of neuralgia and $23.3 \%$ were significantly helped by the drug. ${ }^{108}$ Dosing, however, averaged $6 \mathrm{mg}$ to $8 \mathrm{mg}$ per day, and $80-88 \%$ of the patients experienced somnolence and unsteady gait. Side effects of clonazepam include sedation, ataxia, memory impairment, and risk for dementia with long-term use. Patients can also experience a paradoxical reaction and become agitated and behave aggressively.

\section{Valproate}

Valproate is an anticonvulsant that mediates its effects through blockade of voltage-gated sodium channels and increased levels of GABA. Peiris et al administered valproate to 20 patients with trigeminal neuralgia. ${ }^{109} \mathrm{Six}$ out of 20 patients had no attacks for 6-18 months while, in 3 patients, the frequency and severity of attacks were reduced by at least $50 \%$. In the United States, valproate contains black box warnings for hepatotoxicity, pancreatitis, and fetal malformations. Most commonly people experience weight gain, hair loss, and nausea. Patients may also develop thrombocytopenia or abnormal ammonia levels and elevated liver function tests.

\section{Misoprostol}

Misoprostol is a prostaglandin E1-analogue that was noted in case reports to be efficacious at reducing pain in patients with TN and associated multiple sclerosis. Reder et al noted that misoprostol relieved pain in six of seven patients who had failed to respond to conventional pharmacologic therapy. ${ }^{110}$ Building on those observations, the German Migraine and Headache Society performed an open prospective trial, which enrolled 18 patients with refractory trigeminal neuralgia associated with multiple sclerosis. Fourteen patients showed a reduction of more than $50 \%$ in attack frequency and intensity beginning 5 days after treatment onset. There were only mild and transient drug-related side effects in three patients. One patient stopped taking misoprostol after the study period because of severe menorrhagia. The authors speculate that misoprostol may be exerting its effects through modulation of multiple sclerosis-related inflammation.

\section{Multimodal Therapy}

Patients who fail one medical therapy may be treated with multiple medications working through different medications, which work via different mechanisms. Combination therapy may be significantly more effective than monotherapy and may afford patients significantly longer periods of pain relief without having to resort to percutaneous, or more invasive open surgical procedures.

\section{Percutaneous Approaches}

Percutaneous approaches to the trigeminal nerve usually involve needle localization of the Gasserian ganglion through the foramen ovale. ${ }^{1,111}$ Specific approaches may vary, but in general, variations of the Hartel percutaneous route are used, where a rhizotomy needle is inserted and advanced via fluoroscopic guidance toward the intersection point of medial canthus and approximately $3 \mathrm{~cm}$ anterior to the internal auditory meatus. On lateral view, the needle should be pointed toward the petrous bone and clivus, and should be around $10 \mathrm{~mm}$ posterior to the dorsum sella. Care must be taken to avoid the oral cavity as well as injury to adjacent vascular structures such as the internal carotid artery and jugular vein. ${ }^{112}$ As the needle passes through the foramen ovale, tactile feedback in the form of a give or loss of resistance may be noted. There may also be a reflexive jaw jerk, which occurs due to irritation of motor branches of the trigeminal nerve. In some cases, entry into Meckel's cave may result in CSF flow through the needle when the stylet is withdrawn. The position of the needle may be confirmed with contrast or air injection under live fluoroscopy.

Other methods of percutaneous targeting of the trigeminal nerve include ultrasound or CT guidance. Ultrasound guidance is commonly used for percutaneous targeting of superficial branches of the trigeminal nerve. ${ }^{113-118}$ CTguidance provides excellent visualization of bony structures, and advancements in CT-fluoroscopy have added real-time visualization of needle advancement as an additional benefit. ${ }^{119-123}$ However, increased radiation exposure and costs limit its use to situations where traditional fluoroscopy methods are inadequate for patients with anatomic variability. 


\section{Balloon Compression}

In 1983, Mullen and Lictor first described percutaneous balloon microcompression of the trigeminal ganglion. ${ }^{124}$ The technique involves using a 14 gauge hollow metallic introducer. The introducer is advanced under fluoroscopic guidance to the foramen ovale. A 4 French Fogarty balloon is introduced through the metallic introducer approximately $1 \mathrm{~cm}$ beyond the needle tip. Contrast dye is injected into the balloon under live fluoroscopy and compression is held for 3-6 minutes. The balloon is deflated, and the Fogarty balloon as well as the metallic introducer are removed together with manual pressure at the puncture site. Brown et al demonstrated in a rabbit model of balloon compression of the Gasserian ganglion that large myelinated axons, involved in the sensory trigger, were mostly injured, while small myelinated fibers were relatively preserved. ${ }^{125}$

Skirving et al reported on 496 patients with TN who underwent 531 percutaneous balloon compressions of the trigeminal ganglion between 1980 and $1999 .{ }^{126}$ Of the 522 successful procedures, prompt pain relief was experienced by all but one patient. Recurrence of pain was found in $19.2 \%$ of the patients within 5 years and in $31.9 \%$ over the entire study period. Other studies demonstrate an immediate pain relief range from $80 \%$ to over $90 \%$, but also a pain recurrence rate between $15 \%$ and $50 \%$ over $2-5$ years. ${ }^{127-138}$ Factors which have been shown to affect balloon compression outcomes include the shape of the inflated balloon, the opening pressure of the balloon/ volume of contrast injected, and the length of compression time. ${ }^{127,132,133,139}$ Complications of balloon compression include facial dysesthesias but may also include cranial nerve palsies and acute changes in blood pressure and heart rate due to trigeminal cardiac reflexes. ${ }^{140,141}$

\section{Chemodenervation}

Percutaneous chemodenervation has been described as a potential for treatment for TN as early as in the $1800 \mathrm{~s}$ when Wilfred Harris published a case series of three patients who were treated with alcohol chemodenervation. ${ }^{142}$ Since then, glycerol, phenol, and alcohol have all been described as chemodenervating agents used for TN. While the specific mechanisms of action in providing pain relief are not well understood, the general consensus is that chemical neurolysis causes selective lysis of the axonal sheath in damaged nerve fibers and prevents aberrant firing, or that normalization of temporal summation of synaptic potentials within the trigeminal ganglion causes pain reduction. ${ }^{130,138,143,144}$

Peripheral alcohol injections have been used in the treatment of trigeminal neuralgia since the early 1900s; however, most series have been limited to a few patients. More recently, Han et al described the use of alcohol in 632 TN patients. ${ }^{145}$ They injected the infraorbital nerve, superior orbital nerve, maxillary nerve, mandibular nerve, or a combination of the above. Moreover, $46.9 \%$ of the patients did not require re-treatment and only $33.4 \%$ of the patients had no pain by 5 years. Shah et al described 250 alcohol injections in 100 patients. ${ }^{146}$ Thirty-four $(13.6 \%)$ injections did not achieve pain relief for at least 2 months. Of the successful injections, the mean duration of action was 14.13-8.66 months. McLeod et al reported 278 alcohol injections in 49 patients with a mean of 6 per patient. ${ }^{147}$ Twenty-seven (10\%) achieved pain relief for less than 1 month. Of successful injections, the mean duration of action was 11 months. Complications of alcohol injection have been reported to range from less than $1 \%$ to $33 \%$. Mild complications include transient burning sensation, dysesthesias, while severe reactions include avascular necrosis, facial paresis, cheek mucosal or skin ulceration, diplopia, skin necrosis, trismus, difficulty swallowing, and osteomyelitis.

Due to the potential significant side effects of alcohol, alternative agents have been explored for treatment of TN. Phenol was discovered as a neurolytic agent in $1926,{ }^{148,149}$ and has been used to alleviate spasticity via intrathecal injections. ${ }^{150,151}$ Mechanisms of action include denaturation of protein, loss of cellular fatty content, and separation of the myelin sheath from the axon leading to nonselective neural destruction, muscle atrophy, and necrosis. Jefferson injected performed 37 injections of phenol mixed with glycerin into Meckel's cave. ${ }^{152}$ Excluding 7 failures from technical difficulties, 37\% experienced pain recurrence within 1-2 years after the procedure. Wilkinson reported 60 injections of $10 \%$ phenol in glycerol, which were given to 18 patients. ${ }^{153}$ Forty-six injections were administered into the infraorbital nerve in its canal in the midface, 11 percutaneous injections were administered into the mandibular nerve proximal to the mandibular canal in the ramus of the jaw, and three injections were administered into supraorbital nerves. Eighty-seven percent of injections brought marked or total relief initially. Of those injections that provided initial relief, $37 \%$ continued to provide relief after 1 year and $30 \%$ did so after 2 years. Chronic exposure to phenol may lead to renal 
toxicity, skin lesions, and gastrointestinal effects. Systemic side effects include nausea and vomiting, central nervous system stimulation, and cardiovascular depression. Because of its toxicity profile, phenol's use in chemodenervation has been most often utilized in alleviating pain in end-stage cancer patients. ${ }^{154,155}$

Glycerol is a colorless, odorless, viscous liquid. ${ }^{156} \mathrm{In}$ concentrations above $99 \%$, glycerol is highly hypertonic and causes neurolysis by fragmentation of myelin or directly penetrating the perineurium. ${ }^{157} \mathrm{Xu}$ et al described their experience with 3370 patients and described pain relief in $73 \%$ of the patients after one injection. ${ }^{158}$ The success rate increased with increasing numbers of injections, with an overall success rate of $99.58 \%$ after four injections. Of 2750 patients with follow-up, $21 \%$ of the patients had pain recurrence within 5 years, and the overall rate of pain recurrence over the length of the study was $33 \%$. Other large case series report an initial pain relief rate of 70 to greater than $90 \%{ }^{128,131,137,144,159-165}$ However, $20-40 \%$ of the patients experience pain recurrence within a median of 20-60 months after the procedure. Complications of glycerin rhizotomy are usually related to facial hyperesthesia, hypoalgesia, and dysesthesia. Other perioperative complications include nausea/ vomiting, trigeminal motor weakness, hematoma, meningitis, and optic nerve injury. Hypoesthesia of the superior trigeminal division may result in keratitis ulcers and ocular complications.

\section{Radiofrequency Ablation}

Electrocoagulation to target the trigeminal nerve rootlets was first developed in 1913 by Réthi. Early use of the technique was associated with serious complications, including corneal ulcers requiring enucleation, multiple cranial nerve palsies, carotid injury, cardiac arrest, meningitis, and death. ${ }^{166}$ Subsequent improvements in temperature monitoring, placement technique, and electrode design have made the procedure safer. Needle placement is verified as previously described above with fluoroscopic assistance. The needle obturator is removed, and the electrode is introduced. Electric stimulation is typically achieved at $0.2-1 \mathrm{~V}(50 \mathrm{~Hz}$ for $0.2 \mathrm{~ms})$. The electrode is then replaced with the thermocouple, and lesions are made at a maximum of $0.5 \mathrm{~V}, 75$ cycles per second at $55^{\circ} \mathrm{C}$ to $80^{\circ} \mathrm{C}$ for $30-120 \mathrm{~s}$. The electrode and cannula are then removed. In some cases, selective V2 or V3 targeting with ultrasound guidance via the pterygopalatine fossa may be used. ${ }^{114}$
Several large studies have demonstrated the success of radiofrequency ablation. Wu et al reported outcomes on 1860 patients, with $79 \%$ experiencing immediate pain relief, and $18 \%$ experiencing improved pain. ${ }^{167}$ Pain recurrence was encountered in $11.1 \%$ during the first year; by 2 years, $25 \%$ of the patients had recurrent pain. Kanpolat et al described their 25-year experience treating 1600 patients with 2138 radiofrequency ablation procedures. ${ }^{168}$ Acute pain relief was achieved in $97.6 \%$ of the patients. Early pain recurrence within 6 months was observed in $7.7 \%$ of the patients, and late pain recurrence was observed in an additional $17.4 \%$. Complete pain relief was achieved in $58 \%$ of the patients who underwent a single procedure at 5 years; this number decreased to $52 \%$ at 10 years, and $41 \%$ at 20 years. Complications of radiofrequency ablation include diminished corneal reflex, masseter weakness, dysesthesias, keratitis, and cranial nerve palsies. Rarely, CSF leak, carotid-cavernous fistula, meningitis, and anesthesia dolorosa/trigeminal deafferentation pain may be encountered. ${ }^{120,166-180}$

\section{Combined Glycerol and Radiofrequency Ablation}

Glycerol rhizotomy may be combined with radiofrequency ablation. ${ }^{138}$ Bender et al analyzed 822 patients who underwent glycerol rhizotomy alone compared with glycerol and radiofrequency ablation. ${ }^{181}$ In their series, no significant differences were found in terms of initial or duration of pain relief for those who underwent glycerol rhizotomy only versus those who underwent combined glycerol and radiofrequency ablation. No differences were found in subgroup analyses for patients with multiple sclerosis undergoing glycerol rhizotomy only versus those who underwent combined percutaneous glycerol and radiofrequency ablation.

\section{Other Ablative Approaches Cryoablation}

Cryotherapy for blocking of peripheral nerves was first described in 1976 by Lloyd. ${ }^{182}$ The mechanisms underlying cryotherapy involve temperatures between $-60^{\circ} \mathrm{C}$ and $-140^{\circ} \mathrm{C}$ causing axonotmesis of the affected nerve. Lloyd et al published his experience in six patients with facial pain. The nerves were surgically exposed and cryoablation was applied at $-60^{\circ} \mathrm{C}$. All patients experienced some degree of pain relief with a median duration of only 21 days. Zakrzewska published a series of 145 
patients who underwent cryotherapy, and found the median duration of pain relief to be 6 months. ${ }^{183-185}$ In the same paper, Zakrzewska found that 288 patients who had undergone radiofrequency ablation had a median time to pain recurrence of 24 months. ${ }^{184}$ Pradel found similar results in 19 patients undergoing cryoablation of the infraorbital or inferior alveolar nerve, where 13 patients experienced pain recurrence after 6-12 months. ${ }^{186}$ Nally performed cryotherapy on the peripheral branches of the trigeminal nerve in 42 patients over 3 years; 16 patients experienced pain recurrence between 3 and 9 months requiring retreatment. ${ }^{187}$ There is a lack of systematic study of whether the number of freezing cycles, or whether temperature affects long-term outcome. ${ }^{188}$ Due to overall shorter pain-free survival outcomes compared with other percutaneous techniques, few practitioners offer cryoablation as a first-line treatment for $\mathrm{TN}$ patients.

\section{Non-Ablative Percutaneous Approaches Trigeminal Nerve Blocks}

For patients who have failed medical management, percutaneous interventions may be pursued which include peripheral nerve blocks, chemodenervation, balloon compression, or radiofrequency ablation. Nerve blocks have been shown to provide acute pain relief, sometimes extending to weeks or even months. ${ }^{13,189-191}$ Given the relative rarity of trigeminal neuralgia, there are no large, randomized studies investigating patient response to different injectates. Local anesthetics such as lidocaine and bupivacaine have been used for peripheral nerve blocks, and work by inhibiting voltage-gated sodium channels. Most reports involving local nerve blocks for TN are limited to less than 10 patients. ${ }^{191,192}$ Han et al reported using 10\% lidocaine in infraorbital nerve block, superior orbital nerve block, maxillary nerve (V2) block, mandibular nerve (V3) block or Gasserian ganglion block for patients with TN. ${ }^{193}$ Out of 35 patients treated, 12 patients experienced sustained pain relief more than 24 hours after intervention. For those who experienced some degree of pain relief, the duration of pain relief lasted from 3 weeks to 144 weeks after the procedure. Why some patients experience sustained pain relief longer than expected based on the local anesthetic's duration of action is unknown.

\section{Botulinum A Toxin Injections}

Botulinum A toxin injections have been described in the early 2000s for the treatment of TN. ${ }^{83,194-201}$ Botulinum toxin works by inhibiting acetylcholine release into the neuromuscular junction, and blocks the release of neurotransmitters such as substance $\mathrm{P}$, calcitonin gene-related peptide, and glutamate. ${ }^{202,203}$ Additional mechanisms of action for pain relief include reduction of inflammation, deactivating sodium channels, and inhibiting axonal transport. Piovesan et al injected $13 \mathrm{TN}$ patients subdermally with botulinum A toxin. ${ }^{204}$ An improvement in pain was seen over 10 days, and lasted for the 60-day duration of the study. Turk Boru et al injected 27 patients with 100 units of botulinum A toxin to the maxillary and mandibular nerves. Fifty-five percent of the patients reported improved pain during the first week; this improved to $78 \%$ of the patients reporting improved pain at the second month, and up to $85 \%$ at 6 months. ${ }^{205}$ At 6 months, $44 \%$ were pain free. Complications of botulinum injections include facial weakness and numbness. Due to a paucity of longitudinal data, the long-term results of botulinum injections for $\mathrm{TN}$ are unknown, but the current data suggests that botulinum injections for $\mathrm{TN}$ may be beneficial in cases not responding to medication and may be used before surgery is considered. ${ }^{206}$

\section{Neuromodulation for TN Transcutaneous Electrical Nerve Stimulation}

In 1967, Wall and Street reported the seminal discovery that stimulation of nerves decreased the perception of pain. $^{207}$ The effectiveness of transcutaneous electrical nerve stimulation (TENS) for treating $\mathrm{TN}$, however, is sparse. $^{34,52,207,208}$ TENS therapy for TN involves placing stimulating electrodes in the areas innervated by the second and third branches of the trigeminal nerve, where patients typically experience pain. Yameen et al looked at the effects of different types of TENS therapy specifically for TN that was refractory or partially responsive to drug treatment. ${ }^{209}$ Constant mode TENS therapy where stimulation was supplied continuously throughout sessions was shown to be more effective than burst therapy where stimulation was supplied in pulses. In total, out of $31 \mathrm{TN}$ patients, 26 were responsive to TENS therapy after a follow-up of 3 weeks. No long-term outcomes are reported. This data is supported by Singla et al, in which 30 patients with TN who underwent TENS for 20-40 days. The patients experienced an overall $65 \%$ reduction in pain ratings after 1 month and an $85 \%$ reduction after 3 months. No long-term outcomes are available. ${ }^{210}$ These data show 
that TENS is a potentially non-invasive treatment for TN, but further studies are needed to verify this effect in a randomized, blinded fashion and to study its long-term outcomes.

\section{Peripheral Nerve Stimulation}

In lead-based peripheral nerve stimulation therapy, an electrode array delivers electrical impulses to branches of the trigeminal nerve or the Gasserian ganglion via an implantable pulse generator (IPG). One of 8 patients described by Wall and Street had $\mathrm{TN}$ in the V2 distribution. $^{207}$ Stimulation of the infraorbital nerve for 5 minutes enabled the patient to be pain free for 17 minutes afterwards, although no long-term follow-up is provided. Shelden et al reported the outcomes of three patients with typical trigeminal neuralgia in a V3 distribution who underwent temporal craniotomies for placement of platinum stimulator electrodes on V3211. All 3 experienced complete pain relief for the 3-4-month follow-up period, despite two patients never having received any nerve stimulation at all after implantation. In 1980, Meyerson and Hakansson described the results of Gasserian nerve stimulation with implanted electrodes in six patients, some on whom had atypical TN. ${ }^{212}$ Five patients had follow-up from 6 to 21 months and reported complete or partial pain relief.

More recently, Ellis et al reported on 35 patients who underwent trigeminal branch lead-based stimulation. ${ }^{213}$ Two patients were diagnosed with type $1 \mathrm{TN}$ and 9 were diagnosed with type 2 TN. One patient was diagnosed with symptomatic TN. Though there was one case of a superficial temporal artery pseudoaneurysm from needle injury, results demonstrated an overall benefit of peripheral nerve stimulation on pain relief. Two of the nine type $2 \mathrm{TN}$ patients, both type $1 \mathrm{TN}$ patients, and the symptomatic TN patient responded to trial stimulation. Of the 35 patients in the study, 17 responded to the trial stimulation and 15 of the responders had permanent hardware implantation. Over an average of 15 months of follow-up, 11/15 patients reported improved pain at last follow-up. It was not made clear which of the TN patients had permanent hardware implantation, and the TN patients' specific responses were not specified. Long-term outcomes of peripheral nerve stimulation for $\mathrm{TN}$ treatment require further study and clarification. Complications of the procedure include electrode and extension wire fracture or migration. Permanent lead placement in the face and an unclear duration of benefit limits peripheral nerve stimulation usually for patients with trigeminal neuropathic pain as opposed to $\mathrm{TN}$.

\section{Deep Brain Stimulation}

Although deep brain stimulation (DBS) was first used in the 1950s for improvement of chronic pain, the technique fell out of favor in the late 1990s when two major multicenter trials failed to demonstrate efficacy. ${ }^{214}$ Nonetheless, a substantial body of literature cites the stimulation of periventricular grey (PVG), periaqueductal grey (PAG), and sensory thalamus as potential targeted regions for pain. The mechanism of action is still unclear, but release of endogenous opiates may play a role in pain relief. Nandi et al reported one patient with refractory TN treated with DBS of the PVG and ventroposterolateral thalamic nucleus. $^{215}$ Though the patient ultimately did not undergo IPG implantation, during the trial stimulation she received $33 \%$ reduction in pain. Additional targets have also been tested for TN, such as the posterior hypothalamus. Franzini et al treated five patients with TN secondary to multiple sclerosis and reported that all five patients experienced pain reduction at 1-3 years postoperatively, although only two of the five patients did not require medications. $^{216}$ Given its invasive nature and the need for permanent IPG implantation, DBS remains a salvage procedure for refractory $\mathrm{TN}$.

\section{Focused Ultrasound}

Transcranial MR-guided focused ultrasound surgery is an evolving treatment modality in neurosurgery and has been used in clinical trials to treat chronic pain via thalamotomy and in the treatment of brain tumors. The ExAblate Neuro (InSightec) has 1024 ultrasound transducers, which transmit ultrasound energy through the skull that converges onto a focal spot and causes a highly focused region of heating, thereby creating a lesion in the target tissue. Martin et al utilized the Insightec system to treat nine patients with neuropathic pain, of which one had idiopathic trigeminal neuralgia. ${ }^{217}$ The patient underwent a central lateral thalamotomy. Pain relief 2 days after the intervention ranged from $30 \%$ to $100 \%$ for the 9 patients, but individual data are not available. No long-term outcomes are available from the study. More recently, Monteith et al demonstrated in a cadaveric model that the InSightec system is able to heat up the trigeminal nerve by up to $18^{\circ} \mathrm{C} .^{218}$ Future studies are needed to see if focused ultrasound may be effective in lesioning the trigeminal nerve in patients. 


\section{Motor Cortex Stimulation}

Motor cortex stimulation (MCS) consists of an electrode surgically placed in the epidural or subdural space above the motor cortex connected to an implanted pulse generator. Stimulation of the contralateral motor cortex is postulated to cause corticocortical feedback with inhibition of the active sensory cortex nociceptive neurons, resulting in pain relief. The appeal of MCS comes in part because of a belief that MCS is safer than DBS, but no direct comparisons have been made. MCS for type I or type II TN has rarely been studied, with most reports focusing on neuropathic trigeminal pain. In a 2009 study, Fontaine et al showed that among 44 patients with trigeminal neuropathic pain, 30 saw pain relief of at least $40-50 \% .{ }^{219}$ Eighteen patients were followed for greater than 1 year, and at the last follow-up, half saw pain reduction of $40-50 \%$. The study did not specify which of the patients, if any, had TN. A more recent study in 2015 by Henssen et al reported two patients with type $1 \mathrm{TN}$ and one patient with type $2 \mathrm{TN}$ treated with $\mathrm{MCS}^{220}$ All three TN patients saw pain reduction of at least $60 \% 3$ years after surgery. The report, however, acknowledges that classic trigeminal neuralgia is typically not treated with MCS, and the pain relief that the patients experienced may be due in part to prior interventions. Long-term outcomes of MCS for classic trigeminal neuralgia are not well studied, and future work will be necessary to better characterize its efficacy.

\section{Transcranial Magnetic Stimulation}

Repetitive transcranial magnetic stimulation (rTMS) has also recently arisen as an assessment method of whether a patient may respond well to cortical stimulation. Lefaucheur et al reported that of $12 \mathrm{TN}$ patients for whom surgical treatment was not effective, $58 \%$ had over $30 \%$ reduction in pain after rTMS to the motor cortex. ${ }^{221}$ Khedr et al studied $24 \mathrm{TN}$ patients with refractory pain who received rTMS to the motor cortex. ${ }^{222}$ In the cohort, the pain decreased by roughly $45 \%$ after 2 weeks, and this was significantly better than a control cohort group of patients who received sham therapy. No longterm follow-up was reported. Long-term outcomes of rTMS for classic trigeminal neuralgia are not well studied, and future studies will be necessary to assess the effectiveness of direct or transcranial magnetic stimulation of the motor cortex.

\section{Stereotactic Radiosurgery}

Lars Leksell first described the use of stereotactic radiosurgery in 1951 for TN. ${ }^{223,224}$ Current methods for radiation delivery include Gamma Knife (GK), ${ }^{225-227}$ linear accelerator (LINAC), ${ }^{228-230}$ or CyberKnife (CK). ${ }^{230}$ Gamma Knife uses stereotactic head frame immobilization and requires pins to be placed percutaneously onto the skull under local anesthesia. Stationary radioactive Cobalt-60 gamma-emitting sources are then used to target the treatment area from various angles. LINAC treatment may be performed with either head frame immobilization, or alternatively a face mask may be used. LINAC X-ray emitting sources move around the patient's head in rotational arks, and this delivers the planned radiosurgical dose. CyberKnife treatment requires application of a facial mask. In this case, radiation emitters are mounted to a robotic arm, and can make non-rotational movements around the patient's head.

Tuleasca et al reviewed 6461 patients treated with GK, LINAC, or $\mathrm{CK}^{230}$ For patients undergoing GK, radiation doses ranged from 60 to 97 Gy prescribed at the $100 \%$ isodose line. LINAC patients underwent 50-90 Gy prescribed at the $80 \%$ isodose line, and CK patients underwent $66-90$ Gy prescribed at the $90 \%$ isodose line. Current level II evidence suggests that the minimal effective dose is $70 \mathrm{~Gy}$, and the maximal effective dose is $90 \mathrm{~Gy}$. At doses above 90Gy, the efficacy rate of radiosurgery remains similar, but is associated with a higher frequency of complications.

Targeting for radiosurgery ranges from the anterior/ retrogasserian portion of the trigeminal nerve, to the posterior or root entry zone portions of the trigeminal nerve. A more posterior target close to the root entry zone may include portions of the pons within the $20-30 \%$ isodose line. Multiple studies have compared outcomes between targeting the retrogasserian portion of the trigeminal nerve versus the root entry zone. A pooled analysis of outcomes reported by Matsuda et al. ${ }^{225}$ Park et $\mathrm{al}^{227}$ and Xu et $\mathrm{al}^{230}$ demonstrated that targeting the anterior retrogasserian portion of the trigeminal nerve is associated with similar initial efficacy at pain reduction compared to posterior targeting but has less complications associated with dry eye syndrome, hypesthesias or numbness.

The effect of one versus multiple isocenters, and the effect of the length of cisternal nerve segment treated has been investigated by a number of groups. Flickinger et al reported results from a prospective, double-blind randomized trial including 87 patients treated with 75 Gy using 
one versus two 4-mm isocenters at a retrogasserian target. $^{231}$ These patients were followed for a median of 26 months, and pain relief was similar postoperatively. However, patients who received radiation at two isocenters had significantly increased sensory complications and hypesthesia $(\mathrm{p}=0.018)$. In general, higher doses are more effective at yielding pain relief but cause more numbness, trigeminal deafferentation pain, and anesthesia dolorosa. Unlike other percutaneous or open surgical approaches, pain relief is not immediate for radiosurgery. The times to pain relief ranges from 0 to 480 days, with most authors agreeing that the maximum time for pain relief to be 180 days after treatment. ${ }^{64,225-229,231-246}$ On average, the rates of freedom from pain with or without $\mathrm{TN}$ medication supplementation was found to be $86 \%$ for GK, $88 \%$ for LINAC, and $79 \%$ for $\mathrm{CK} .{ }^{230}$ This was not statistically different. Accounting strictly for patients who were pain free and required no additional medications, the ability for radiosurgery to achieve a pain-free response falls to $52 \%$ for GK, $43 \%$ for LINAC, and 58\% for CK. Median recurrence rates for facial pain were $23 \%$ for $\mathrm{GK}, 29 \%$ for LINAC, and $27 \%$ for $\mathrm{CK}$. The mean times to recurrence ranged from 6 to 48 months for GK, 7.5-20.4 months for LINAC, and 9 months for CK. Few studies report the long-term rates of pain control, but at 7 years, rates of pain control range from $22 \%$ to $60 \%$. At 10 years, rates of pain control fall to well below $50 \%$. For patients with multiple sclerosis, the rates of pain-free survival are worse, and the rates of pain recurrence are higher.

Complications of radiosurgery for $\mathrm{TN}$ include facial hypesthesia, dysesthesia, keratitis/corneal damage due to loss of sensation, and dry eye. ${ }^{225}$ The median rates of hypesthesia are 19\% for GK, 29\% for LINAC, and 19\% for CK. The onset of these complications may range from 1 to 94 months.

Although determining the best timing of radiosurgery after pain onset still requires further study, recent work has shown that undergoing GK earlier in the course of TN pain onset may lead to improved clinical outcomes and may reduce treatment with medication. ${ }^{246-248}$

\section{Open Surgery}

\section{Microvascular Decompression (MVD)}

In 1856, Carnochan described the first trans-antral approach to the trigeminal ganglion. ${ }^{3}$ In 1891, Horsley described sectioning the intradural nerve fibers of the trigeminal nerve to treat trigeminal neuralgia. ${ }^{249}$ In 1892 ,
Hartley and Krause described an extradural approach to trigeminal nerve rootlet sectioning at the foramen ovale and rotundum. ${ }^{4}$ This approach was further modified by Frazier and Spiller, who attempted to divide select portions of the nerve to minimize morbidity. In 1925, Walter Dandy advocated for partial sectioning of the trigeminal nerve via a posterior fossa approach. During those operations, he observed that the nerve was compressed by vascular structures, and in 1932, proposed that vascular compression was the pathophysiological mechanism underlying TN. 4,250,251 Peter Jannetta, with the use of the operating microscope, was able to confirm this theory in $1967 .^{252}$

Microvascular decompression is a surgical procedure that involves a suboccipital craniectomy and microsurgical dissection around the trigeminal nerve. Identification of a compressive artery allows for the placement of a Teflon (polytetrafluoroethylene) or Ivalon (polyvinyl alcohol) pledget to separate the nerve from the offending artery. $^{253}$ Others have reported the creation of a sling with sutures, glue, ${ }^{254}$ or the tentorium as a method of arterial decompression. ${ }^{255}$ In cases where a vein is causing trigeminal compression, bipolar cautery is used to divide the vein.

The outcomes following MVD are favorable with systematic reviews estimating greater than $90 \%$ rates of initial freedom from pain. ${ }^{62,175,245,254,256-263}$ In the original seminal paper of Barker et al, 1185 patients underwent microvascular decompression, of which 1155 were followed for 1 year or more. ${ }^{256}$ Most postoperative pain recurrences took place in the first two years after surgery. Eleven percent underwent second operations for the recurrences. Ten years after surgery, $70 \%$ of the patients were pain free and did not require medication supplementation for pain control. An additional 4\% had occasional pain that did not require long-term medication. The most recent estimates of MVD outcomes estimate $80 \%$ will still be pain free at 1 year, $75 \%$ at 3 years and $73 \%$ at 5 years. ${ }^{175,245,259,261,263,264}$ Commensurate with these findings, Holste et al recently performed a meta-analysis of 3897 patients from 46 studies, and found that $76 \%$ were pain free at a follow-up of $1.7 \pm 1.3$ years. ${ }^{265}$ Factors associated with improved outcomes included a shorter duration of symptoms, Burchiel type I pain, and arterial as opposed to venous compression.

Complications following MVD may occur in up to $20 \%$ of the patients, although serious complications are rare. $^{245,259,261,263}$ Cranial nerve-related complications bear special consideration in the case of MVD, as cranial 
nerves IV through XII are exposed via the operative approach. Numbness and dysesthesias in the trigeminal nerve occur in a significant minority of patients, ranging from $5 \%$ to $10 \%$. Diplopia due to fourth or sixth nerve manipulation is often transient and facial nerve palsy is rare $(<1 \%)$. Hearing loss ranges from $1-20 \%$, depending on audiometry or subjective reports. ${ }^{260}$ Most high-volume centers monitor brain stem auditory evoked responses in an effort to reduce the risk of hearing loss. ${ }^{266,267}$ Other complications include cerebrospinal fluid (CSF) leak approximately in $3-4 \%$, and this may be managed conservatively with a lumbar drain or ultimately via CSF shunting or a wound revision. Infections are rare and occur at a similar rate compared with other craniotomies. Other rare complications include aseptic meningitis, postoperative hemorrhage, and stroke. ${ }^{261,268,269}$ Mortality associated with the procedure is estimated at $0.2 \%$.

When compared with percutaneous techniques, MVD is a more invasive procedure requiring the ability to tolerate general anesthesia. However, it is generally associated with a more durable response in mitigating pain, and does not preclude the ability to pursue percutaneous interventions as a salvage procedure. Compared with percutaneous techniques, MVDs have a lower rate of hypoesthesia and dysesthesia complications and have a longer sustained rate of pain control. As a result, increasingly neurosurgical providers are recommending MVD as a first-line surgical intervention after failure of medical therapy.

\section{Partial Sensory Rhizotomy and Intraoperative Glycerin Rhizotomy}

The absence of neurovascular contact on MRI is not a contraindication to surgery. Up to $30 \%$ of the patients presenting with Burchiel Type 1, episodic pain has no evidence of neurovascular compression on imaging. On average, these patients are more likely to be younger and female. For these patients, posterior fossa exploration with internal neurolysis of the trigeminal nerve by separating nerve fascicles via microsurgical techniques may provide pain relief. $^{263,270-272}$ Pain-free outcomes for partial sensory rhizotomy are similar to slightly worse than those for MVD patients, although patients undergoing partial sensory rhizotomy are more likely to experience postoperative sensory complaints, presumably due to direct internal neurolysis of the nerve. ${ }^{258,273,274}$ Intraoperative glycerin rhizotomy has also been described for patients without vascular compression. Kim et al described 74 patients who underwent MVD with glycerin injections. And, $95.9 \%$ of the patients experienced pain improvement after surgery, and 17.6\%, however, developed burning pain following surgery. ${ }^{275}$ Not surprisingly, complications related to partial sensory rhizotomies and intraoperative glycerin injections are similar compared with MVDs, as the surgical approach is essentially identical.

\section{Peripheral Neurectomy}

Peripheral neurectomy involves the surgical disconnection of peripheral branches of the trigeminal nerve. ${ }^{276-283}$ The procedure is usually performed as an outpatient procedure for patients who have failed medical therapy, or those who have severe medical comorbidities and are unable to tolerate a suboccipital craniectomy for microvascular decompression. The procedure is relatively low cost and does not require extensive surgical, anesthetic, or technological infrastructure, although the outcomes are inferior to MVD. It is thus still cited as a reasonable option for patients who live in limited geographic or socioeconomic conditions.

The procedure has been reported for the supraorbital, supratrochlear, infratrochlear, lacrimal nerves, infraorbital nerve, inferior alveolar, lingual, and mental nerves. ${ }^{278-280}$ By definition, peripheral neurectomy completely divides the nerve, and so dense numbness along the distribution of the ablated nerve is inevitable and expected.

Initial rates of pain relief for peripheral neurectomies range from $70 \%$ to over $90 \% .^{276,277,281-283}$ Pain recurrence is thought to be secondary to peripheral nerve regeneration. Attempts have been made to prevent pain recurrence and nerve regeneration via obliteration of the exiting nerve's bony foramen, or where nerves are sectioned. ${ }^{280}$ Materials that have been used include steel screws, bone, bone wax, silver plugs, or fat. Despite these efforts, a large number of patients experience pain recurrence over 12-24 months. Recurrent pain may be treated with a second neurectomy; however, repeat procedures often afford less durable pain relief compared with the index procedure. ${ }^{278}$

\section{TN and Multiple Sclerosis}

$\mathrm{TN}$ can be associated with multiple sclerosis (MS), and is often associated with a pontine demyelinating plaque. Truini et al found that the frequency of neurovascular compression and its association with pontine demyelinating plaque was found to be higher on the affected than on the unaffected side ( $54 \%$ vs $0 \% ; p=0.0001)$ after screening $1628 \mathrm{MS}$ patients. $^{59}$ The authors proposed that 
neurovascular compression, along with a pontine demyelinating plaque in tandem, may play a two-hit mechanism underlying TN pathophysiology in MS patients. Thus, the first-order neurons of the trigeminal nerve in MS patients with TN suffer not only inflammatory demyelination due to autoimmune mechanisms but also mechanical demyelination due to neurovascular compression. ${ }^{54}$

Treatment of TN patients with MS begins with pharmacological treatment, although there are no placebocontrolled studies specifically for MS patients. ${ }^{48,59,110,284,285}$ Existing studies are small, openlabel trials that are based on carbamazepine, lamotrigine, gabapentin, topiramate, misoprostol or combination therapies. ${ }^{48,52,54,57,286}$ For MS patients who fail pharmacological therapy, percutaneous, surgical, and radiosurgical options exist. Similar to pharmacological interventions, however, studies in MS patients with TN are short- and long-term outcomes are not well described. In general, however, percutaneous and surgical interventions are both are less effective in terms of postoperative pain improvement and sustained pain relief rates. ${ }^{48,54,57,59,287}$ Moreover, pain recurrence rates are higher in the treatment of MS-related TN pain compared with classic TN pain. Thus, in line with the two-hit hypothesis in MS-related TN suggests that patients with inflammatory demyelinating disease, coupled with mechanical injury to the nerve, represent a particularly challenging subgroup of $\mathrm{TN}$ patients.

\section{Future Considerations}

To date, trigeminal neuralgia is a clinical diagnosis that does not require imaging or laboratory correlation, though imaging may be helpful for excluding tumor and other diseases related to trigeminal pain. Although the majority of patients present with Type I TN involving neurovascular compression, a substantial number of patients nonetheless have Type II TN pain, or have Type I TN pain but without evidence of nerve compression. Why these patients experience pain, and the molecular mechanisms that distinguish Type I TN pain from Type II TN pain, still remains to be elucidated. Whether these distinct mechanisms arise from differential stimuli distal to the root entry zone, or whether the difference lies in central mechanisms of pain interpretation is also unknown. The fact that a subset of patients with multiple sclerosis uniformly derives less benefit from all medical and surgical interventions implies that neuroinflammation may play a role in disease pathogenesis and severity. Further studies will be needed to define the neuronal-glial interface in trigeminal neuralgia, and a more precise mechanistic understanding of TN will hopefully allow for the development of novel and more effective therapeutics.

\section{Conclusions}

This review broadly summarizes over 150 years of collective clinical experience in the treatment of trigeminal neuralgia. What is increasingly clear is that there is no catch-all medical or surgical intervention that is effective for all patients with trigeminal neuralgia, likely reflective of the fact that TN is likely a heterogenous group of disorders that jointly manifests in facial pain. The firstline treatment for TN remains anticonvulsants due to a long history of use and relatively tolerable side-effects. Patients who fail medical therapy have a range of surgical options available to them. In general, microvascular decompression is a safe and effective procedure with immediate and durable outcomes. Patients who are unable to tolerate general anesthesia or whose medical comorbidities preclude a suboccipital craniectomy may benefit from percutaneous methodologies including glycerin or radiofrequency ablation, or both. For patients with iatrogenic bleeding diathesis due to blood thinning medications who are otherwise ineligible for any type of invasive procedures, or for those who are unwilling to undergo surgically invasive procedures, radiosurgery may be an excellent option-provided the patient is counseled ahead of time that maximum pain relief will take on the order of months to achieve. Finally, peripheral neurectomies continue to provide an inexpensive and resourcesparing alternative to pain relief for a majority of patients in geographic locations with limited economic and medical resources. Ultimately, elucidation of the molecular mechanisms underlying trigeminal neuralgia will pave the way for novel, more effective and less invasive therapies.

\section{Disclosure}

The authors report no conflicts of interest in this work.

\section{References}

1. Abd-Elsayed A. Trigeminal Nerve Pain: A Guide to Clinical Management. 1st ed. Springer International Publishing; 2021.

2. Cole CD, Liu JK, Apfelbaum RI. Historical perspectives on the diagnosis and treatment of trigeminal neuralgia. Neurosurg Focus. 2005;18 (5):E4. doi:10.3171/foc.2005.18.5.5 
3. Carnochan JM. On Tic Douloureux: "the painful affection of the face, Dolor Faciei Crucians," of Fothergill, with a new operation for its cure. Am J Dent Sci. 1860;10(2):254.

4. Patel SK, Liu JK. Overview and history of trigeminal neuralgia. Neurosurg Clin N Am. 2016;27(3):265-276. doi:10.1016/j. nec.2016.02.002

5. Headache Classification Committee of the International Headache Society (IHS). The international classification of headache disorders, 3rd edition. Cephalalgia. 2018;38(1):1-211. doi:10.1177/ 0333102417738202

6. Abd-Elsayed A. Pain: A Review Guide. 1st ed. Cham: Springer International Publishing: Imprint: Springer; 2019.

7. Petersen E, Suen JY. Diagnosis and Management of Head and Face Pain: A Practical Approach. 1st ed. Cham: Springer International Publishing: Imprint: Springer; 2018.

8. Burchiel KJ. A new classification for facial pain. Neurosurgery. 2003;53(5):1164-1166; discussion 1166-1167. doi:10.1227/01. NEU.0000088806.11659.D8

9. Cruccu G, Finnerup NB, Jensen TS, et al. Trigeminal neuralgia: new classification and diagnostic grading for practice and research. Neurology. 2016;87(2):220-228. doi:10.1212/ WNL.0000000000002840

10. Cruccu G, Gronseth G, Alksne J, et al. AAN-EFNS guidelines on trigeminal neuralgia management. Eur J Neurol. 2008;15 (10):1013-1028. doi:10.1111/j.1468-1331.2008.02185.x

11. Cornelissen P, van Kleef M, Mekhail N, Day M, van Zundert J. Evidence-based interventional pain medicine according to clinical diagnoses. 3. Persistent idiopathic facial pain. Pain Pract. 2009;9 (6):443-448. doi:10.1111/j.1533-2500.2009.00332.x

12. Eller JL, Raslan AM, Burchiel KJ. Trigeminal neuralgia: definition and classification. Neurosurg Focus. 2005;18(5):E3. doi:10.3171/foc.2005.18.5.4

13. Dach F, Eckeli AL, Ferreira Kdos S, Speciali JG. Nerve block for the treatment of headaches and cranial neuralgias - A practical approach. Headache. 2015;55(Suppl 1):59-71. doi:10.1111/ head. 12516

14. Katusic S, Williams DB, Beard CM, Bergstralh EJ, Kurland LT. Epidemiology and clinical features of idiopathic trigeminal neuralgia and glossopharyngeal neuralgia: similarities and differences, Rochester, Minnesota, 1945-1984. Neuroepidemiology. 1991;10 (5-6):276-281. doi:10.1159/000110284

15. Patel NM. Neuroanatomy, Spinal Trigeminal Nucleus. Treasure Island (FL): StatPearls; 2020.

16. Zakrzewska JM, Chen HI, Lee JYK. Trigeminal and glossopharyngeal neuralgia. In: McMahon SB, editor. Wall and Melzack's Textbook of Pain. Amsterdam: Elsevier; 2013.

17. Nolph MB, Dion MW. Raeder's syndrome associated with internal carotid artery dilation and sinusitis. Laryngoscope. 1982;92 (10 Pt 1):1144-1148. doi:10.1288/00005537-198210000-00008

18. Raeder JG. "Paratrigeminal" paralysis of oculo-pupillary sympathetic. Brain. 1924;47:149-158. doi:10.1093/brain/47.2.149

19. Shoja MM, Tubbs RS, Ghabili K, Loukas M, Oakes WJ, CohenGadol AA. Johan Georg Raeder (1889-1959) and paratrigeminal sympathetic paresis. Childs Nerv Syst. 2010;26(3):373-376. doi:10.1007/s00381-009-0965-9

20. Solomon S. Raeder syndrome. Arch Neurol. 2001;58(4):661-662. doi:10.1001/archneur.58.4.661

21. Solomon S, Lustig JP. Benign Raeder's syndrome is probably a manifestation of carotid artery disease. Cephalalgia. 2001;21:1-11. doi:10.1046/j.1468-2982.2001.00139.x

22. Boureau F, Legallicier P, Kabir-Ahmadi M. Tramadol in post-herpetic neuralgia: a randomized, double-blind, placebo-controlled trial. Pain. 2003;104(1-2):323-331. doi:10.1016/S0304-3959(03)00020-4

23. Feller L, Jadwat Y, Bouckaert M. Herpes zoster post-herpetic neuralgia. SADJ. 2005;60(10):432, 436-437.
24. Feller L, Khammissa RAG, Fourie J, Bouckaert M, Lemmer J. Postherpetic neuralgia and trigeminal neuralgia. Pain Res Treat. 2017;2017:1681765.

25. Hadley GR, Gayle JA, Ripoll J, et al. Post-herpetic neuralgia: a review. Curr Pain Headache Rep. 2016;20(3):17. doi:10.1007/ s11916-016-0548-x

26. Nalamachu S, Morley-Forster P. Diagnosing and managing postherpetic neuralgia. Drugs Aging. 2012;29(11):863-869. doi:10.1007/s40266-012-0014-3

27. Sampathkumar P, Drage LA, Martin DP. Herpes zoster (shingles) and postherpetic neuralgia. Mayo Clin Proc. 2009;84(3):274-280. doi: $10.4065 / 84.3 .274$

28. Schutzer-Weissmann J, Farquhar-Smith P. Post-herpetic neuralgia - A review of current management and future directions. Expert Opin Pharmacother. 2017;18(16):1739-1750. doi:10.1080/ 14656566.2017.1392508

29. Watson PNC, Evans RJ, Watt VR, Birkett N. Post-herpetic neuralgia: 208 cases. Pain. 1988;35(3):289-297. doi:10.1016/03043959(88)90139-X

30. Almoznino G, Benoliel R, Sharav Y, Haviv Y. Sleep disorders and chronic craniofacial pain: characteristics and management possibilities. Sleep Med Rev. 2017;33:39-50. doi:10.1016/j. smrv.2016.04.005

31. Benoliel R, Zadik Y, Eliav E, Sharav Y. Peripheral painful traumatic trigeminal neuropathy: clinical features in 91 cases and proposal of novel diagnostic criteria. J Orofac Pain. 2012;26 (1):49-58.

32. Haythornthwaite JA, Benrud-Larson LM. Psychological aspects of neuropathic pain. Clin J Pain. 2000;16(2 Suppl):S101-S105. doi:10.1097/00002508-200006001-00017

33. Smith JH, Cutrer FM. Numbness matters: a clinical review of trigeminal neuropathy. Cephalalgia. 2011;31(10):1131-1144. doi:10.1177/0333102411411203

34. Weber K. Neuromodulation and devices in trigeminal neuralgia. Headache. 2017;57(10):1648-1653. doi:10.1111/head.13166

35. Linkov G, Morris LG, Shah JP, Kraus DH. First bite syndrome: incidence, risk factors, treatment, and outcomes. Laryngoscope. 2012;122(8):1773-1778. doi:10.1002/lary.23372

36. Lauria G, Majorana A, Borgna M, et al. Trigeminal small-fiber sensory neuropathy causes burning mouth syndrome. Pain. 2005;115(3):332-337. doi:10.1016/j.pain.2005.03.028

37. Rozen TD, Fishman RS. Cluster headache in the United States of America: demographics, clinical characteristics, triggers, suicidality, and personal burden. Headache. 2012;52(1):99-113. doi:10.1111/j.1526-4610.2011.02028.x

38. Allsop MJ, Twiddy M, Grant H, et al. Diagnosis, medication, and surgical management for patients with trigeminal neuralgia: a qualitative study. Acta Neurochir (Wien). 2015;157 (11):1925-1933. doi:10.1007/s00701-015-2515-4

39. Benoliel R. Trigeminal autonomic cephalgias. Br J Pain. 2012;6 (3):106-123. doi:10.1177/2049463712456355

40. Feinmann C, Newton-John T. Psychiatric and psychological management considerations associated with nerve damage and neuropathic trigeminal pain. J Orofac Pain. 2004;18(4):360-365.

41. Zakrzewska JM, Linskey ME. Trigeminal neuralgia. BMJ. 2014;348:g474. doi:10.1136/bmj.g474

42. Benoliel R, Eliav E, Sharav Y. Self-reports of pain-related awakenings in persistent orofacial pain patients. J Orofac Pain. 2009;23(4):330-338.

43. Carlson CR. Psychological factors associated with orofacial pains. Dent Clin North Am. 2007;51(1):145-160, vii. doi:10.1016/j.cden.2006.09.001

44. Mathisen LC, Skjelbred P, Skoglund LA, Oye I. Effect of ketamine, an NMDA receptor inhibitor, in acute and chronic orofacial pain. Pain. 1995;61(2):215-220. doi:10.1016/0304-3959(94) 00170-J 
45. Panneton WM, Pan B, Gan Q. Somatotopy in the medullary dorsal horn as a basis for orofacial reflex behavior. Front Neurol. 2017;8:522. doi:10.3389/fneur.2017.00522

46. Siqueira SR, Teixeira MJ, De siqueira JT. Severe psychosocial compromise in idiopathic trigeminal neuralgia: case report. Pain Med. 2010;11(3):453-455. doi:10.1111/j.1526-4637.2010.00813.x

47. Zhao CH, Stillman MJ, Rozen TD. Traditional and evidence-based acupuncture in headache management: theory, mechanism, and practice. Headache. 2005;45(6):716-730. doi:10.1111/j.1526-4610.2005.05139.x

48. Foley PL, Vesterinen HM, Laird BJ, et al. Prevalence and natural history of pain in adults with multiple sclerosis: systematic review and meta-analysis. Pain. 2013;154(5):632-642. doi:10.1016/j. pain.2012.12.002

49. Gatchel RJ, Peng YB, Peters ML, Fuchs PN, Turk DC. The biopsychosocial approach to chronic pain: scientific advances and future directions. Psychol Bull. 2007;133(4):581-624. doi:10.1037/0033-2909.133.4.581

50. Katusic S, Beard CM, Bergstralh E, Kurland LT. Incidence and clinical features of trigeminal neuralgia, Rochester, Minnesota, 1945-1984. Ann Neurol. 1990;27(1):89-95. doi:10.1002/ ana.410270114

51. MacDonald BK, Cockerell OC, Sander JW, Shorvon SD. The incidence and lifetime prevalence of neurological disorders in a prospective community-based study in the UK. Brain. 2000;123(Pt 4):665-676. doi:10.1093/brain/123.4.665

52. Amatya B, Young J, Khan F. Non-pharmacological interventions for chronic pain in multiple sclerosis. Cochrane Database Syst Rev. 2018;12:CD012622.

53. Comi G, Filippi M, Rovaris M, Leocani L, Medaglini S, Locatelli T. Clinical, neurophysiological, and magnetic resonance imaging correlations in multiple sclerosis. J Neurol Neurosurg Psychiatry. 1998;64(Suppl 1):S21-S25.

54. Di Stefano G, Maarbjerg S, Truini A. Trigeminal neuralgia secondary to multiple sclerosis: from the clinical picture to the treatment options. $J$ Headache Pain. 2019;20(1):20. doi:10.1186/s10194-019-0969-0

55. Fields HL. Treatment of trigeminal neuralgia. $N$ Engl J Med. 1996;334:1125-1126. doi:10.1056/NEJM199604253341709

56. Love S, Coakham HB. Trigeminal neuralgia: pathology and pathogenesis. Brain. 2001;124(Pt 12):2347-2360. doi:10.1093/ brain/124.12.2347

57. Maarbjerg S, Di Stefano G, Bendtsen L, Cruccu G. Trigeminal neuralgia - diagnosis and treatment. Cephalalgia. 2017;37 (7):648-657. doi:10.1177/0333102416687280

58. McMillan R. Trigeminal neuralgia - a debilitating facial pain. Rev Pain. 2011;5(1):26-34. doi:10.1177/204946371100500105

59. Truini A, Prosperini L, Calistri V, et al. A dual concurrent mechanism explains trigeminal neuralgia in patients with multiple sclerosis. Neurology. 2016;86(22):2094-2099. doi:10.1212/ WNL.0000000000002720

60. Buck K, Christensen H, Bazinski M. Systemic Lidocaine for the Treatment of Pain - Adult/Pediatric - Inpatient/Ambulatory/ Emergency Department Clinical Practice Guideline. Madison, WI: UW Health Center for Clinical Knowledge Management; 2019.

61. Linskey ME. 143 pediatric trigeminal neuralgia $(\mathrm{TN})$ : results with early microvascular decompression (MVD). Neurosurgery. 2017;64(CN suppl 1):234. doi:10.1093/neuros/nyx417.143

62. Resnick DK, Levy EI, Jannetta PJ. Microvascular decompression for pediatric onset trigeminal neuralgia. Neurosurgery. 1998;43 (4):804-807; discussion 807-808. doi:10.1097/00006123199810000-00047

63. Bendtsen L, Zakrzewska JM, Abbott J, et al. European Academy of Neurology guideline on trigeminal neuralgia. Eur $J$ Neurol. 2019;26(6):831-849. doi:10.1111/ene.13950
64. Erbay SH, Bhadelia RA, Riesenburger R, et al. Association between neurovascular contact on MRI and response to gamma knife radiosurgery in trigeminal neuralgia. Neuroradiology. 2006;48(1):26-30. doi:10.1007/s00234-005-0008-5

65. Hughes MA, Frederickson AM, Branstetter BF, Zhu X, Sekula RF. MRI of the trigeminal nerve in patients with trigeminal neuralgia secondary to vascular compression. AJR Am J Roentgenol. 2016;206(3):595-600. doi:10.2214/AJR.14.14156

66. Leal PR, Hermier M, Froment JC, Souza MA, Cristino-Filho G, Sindou M. Preoperative demonstration of the neurovascular compression characteristics with special emphasis on the degree of compression, using high-resolution magnetic resonance imaging: a prospective study, with comparison to surgical findings, in 100 consecutive patients who underwent microvascular decompression for trigeminal neuralgia. Acta Neurochir (Wien). 2010;152 (5):817-825.

67. Seeburg DP, Northcutt B, Aygun N, Blitz AM. The role of imaging for trigeminal neuralgia: a segmental approach to high-resolution MRI. Neurosurg Clin N Am. 2016;27 (3):315-326. doi:10.1016/j.nec.2016.02.004

68. Burke WJ, Grant JM, Selby G. The treatment of trigeminal neuralgia: a clinical trial of carbamazepine ("Tegretol"). Med J Aust. 1965;1(14):494 498. doi:10.5694/j.1326-5377.1965.tb71862.x

69. Reynolds EH, Trimble MR. Adverse neuropsychiatric effects of anticonvulsant drugs. Drugs. 1985;29(6):570-581. doi:10.2165/ 00003495-198529060-00004

70. Krafft RM. Trigeminal neuralgia. Am Fam Physician. 2008;77 (9):1291-1296.

71. Zakrzewska JM, Linskey ME. Trigeminal neuralgia. BMJ Clin Evid. 2009;2009:348.

72. Qin Z, Xie S, Mao Z, et al. Comparative efficacy and acceptability of antiepileptic drugs for classical trigeminal neuralgia: a Bayesian network meta-analysis protocol. BMJ Open. 2018;8 (1):1. doi:10.1136/bmjopen-2017-017392

73. Rockliff BW, Davis EH. Controlled sequential trials of carbamazepine in trigeminal neuralgia. Arch Neurol. 1966;15(2):129-136. doi:10.1001/archneur.1966.00470140019003

74. Killian JM, Fromm GH. Carbamazepine in the treatment of neuralgia. Use of side effects. Arch Neurol. 1968;19 (2):129-136. doi:10.1001/archneur.1968.00480020015001

75. Nicol CF. A four year double-blind study of tegretol in facial pain. Headache. 1969;9(1):54-57. doi:10.1111/j.1526-4610.1969. hed0901054.x

76. Sindrup SH, Jensen TS. Pharmacotherapy of trigeminal neuralgia. Clin J Pain. 2002;18(1):22-27. doi:10.1097/00002508200201000-00004

77. Gomez-Arguelles JM, Dorado R, Sepulveda JM, et al. Oxcarbazepine monotherapy in carbamazepine-unresponsive trigeminal neuralgia. J Clin Neurosci. 2008;15(5):516-519. doi:10.1016/j.jocn.2007.04.010

78. Gronseth G, Cruccu G, Alksne J, et al. Practice parameter: the diagnostic evaluation and treatment of trigeminal neuralgia (an evidence-based review): report of the Quality Standards Subcommittee of the American Academy of Neurology and the European Federation of Neurological Societies. Neurology. 2008;71(15):1183-1190. wnl.0000326598.83183.04

79. Debta FM, Ghom AG, Shah JS, Debta P. A comparative study between oxcarbazepine and gabapentin regarding therapeutic efficiency and tolerability in the treatment of trigeminal neuralgia. J Indian Acad Oral Med Radiol. 2010;22(1):10-17. doi:10.5005/ jp-journals-10011-1003

80. Al-Quliti KW. Update on neuropathic pain treatment for trigeminal neuralgia. The pharmacological and surgical options. Neurosciences (Riyadh). 2015;20(2):107-114. doi:10.17712/ nsj.2015.2.20140501 
81. Bergouignan M. Cures heureuses de neurologies essentielles par le dephenyl hydantoinate de sounde. Rev Laryngol Otol Rhinol. 1942;63:34-41.

82. Bergouignan M, D'Aulnay N. [Effect of diphenyl-hydantoinate salt on essential trigeminal neuralgia]. Rev Otoneuroophtalmol. 1951;23(7):427-431. French.

83. Moore D, Chong MS, Shetty A, Zakrzewska JM. A systematic review of rescue analgesic strategies in acute exacerbations of primary trigeminal neuralgia. Br J Anaesth. 2019;123(2):e385e396. doi:10.1016/j.bja.2019.05.026

84. Blom S. Trigeminal neuralgia: its treatment with a new anticonvulsant drug (G-32883). Lancet. 1962;1(7234):839-840. doi:10.1016/S0140-6736(62)91847-0

85. Blom S. Tic douloureux treated with new anticonvulsant; experiences with G 32883. Arch Neurol. 1963;9:285-290. doi:10.1001/ archneur.1963.00460090091009

86. Cheshire WP. Fosphenytoin: an intravenous option for the management of acute trigeminal neuralgia crisis. J Pain Symptom Manage. 2001;21(6):506-510. doi:10.1016/S0885-3924(01) 00269-X

87. Vargas A, Thomas K. Intravenous fosphenytoin for acute exacerbation of trigeminal neuralgia: case report and literature review. Ther Adv Neurol Disord. 2015;8(4):187-188. doi:10.1177/ 1756285615583202

88. Tate R, Rubin LM, Krajewski KC. Treatment of refractory trigeminal neuralgia with intravenous phenytoin. Am J Health Syst Pharm. 2011;68(21):2059-2061. doi:10.2146/ajhp100636

89. Fromm GH, Chattha AS, Terrence CF, Glass JD. Role of inhibitory mechanisms in trigeminal neuralgia. Neurology. 1981;31 (6):683-687. doi:10.1212/WNL.31.6.683

90. Fromm GH, Terrence CF, Chattha AS. Baclofen in the treatment of trigeminal neuralgia: double-blind study and long-term follow-up. Ann Neurol. 1984;15(3):240-244. doi:10.1002/ ana.410150306

91. Fromm GH, Terrence CF, Chattha AS, Glass JD. Baclofen in trigeminal neuralgia: its effect on the spinal trigeminal nucleus: a pilot study. Arch Neurol. 1980;37(12):768-771. doi:10.1001/ archneur.1980.00500610048007

92. Fromm GH, Terrence CF, Maroon JC. Trigeminal neuralgia. Current concepts regarding etiology and pathogenesis. Arch Neurol. 1984;41(11):1204-1207. doi:10.1001/ archneur.1984.04050220102026

93. Zakrzewska JM, Chaudhry Z, Nurmikko TJ, Patton DW, Mullens LE. Lamotrigine (lamictal) in refractory trigeminal neuralgia: results from a double-blind placebo controlled crossover trial. Pain. 1997;73(2):223-230. doi:10.1016/S0304-3959(97) 00104-8

94. Lunardi G, Leandri M, Albano C, et al. Clinical effectiveness of lamotrigine and plasma levels in essential and symptomatic trigeminal neuralgia. Neurology. 1997;48(6):1714-1717.

95. Rustagi A, Roychoudhury A, Bhutia O, Trikha A, Srivastava MV. Lamotrigine versus pregabalin in the management of refractory trigeminal neuralgia: a randomized open label crossover trial. J Maxillofac Oral Surg. 2014;13(4):409-418. doi:10.1007/ s12663-013-0513-8

96. Lechin F, van der Dijs B, Lechin ME, et al. Pimozide therapy for trigeminal neuralgia. Arch Neurol. 1989;46(9):960-963.

97. Vogl C, Mochida S, Wolff C, Whalley BJ, Stephens GJ. The synaptic vesicle glycoprotein 2A ligand levetiracetam inhibits presynaptic $\mathrm{Ca} 2+$ channels through an intracellular pathway. Mol Pharmacol. 2012;82(2):199-208. doi:10.1124/ mol.111.076687

98. Jorns TP, Johnston A, Zakrzewska JM. Pilot study to evaluate the efficacy and tolerability of levetiracetam (Keppra) in treatment of patients with trigeminal neuralgia. Eur J Neurol. 2009;16 (6):740-744. doi:10.1111/j.1468-1331.2009.02585.x
99. Mitsikostas DD, Pantes GV, Avramidis TG, et al. An observational trial to investigate the efficacy and tolerability of levetiracetam in trigeminal neuralgia. Headache. 2010;50 (8):1371-1377. doi:10.1111/j.1526-4610.2010.01743.x

100. Raju Sagiraju HK, Wang CP, Amuan ME, Van Cott AC, Altalib HH, Pugh MJV. Antiepileptic drugs and suicide-related behavior: is it the drug or comorbidity? Neurol Clin Pract. 2018;8 (4):331-339. doi:10.1212/CPJ.0000000000000489

101. Zhang M, Gao CX, Ma KT, et al. A meta-analysis of therapeutic efficacy and safety of gabapentin in the treatment of postherpetic neuralgia from randomized controlled trials. Biomed Res Int. 2018;2018:7474207.

102. Ta PCP, Dinh HQ, Nguyen K, Lin S, Ong YL, Ariyawardana A. Efficacy of gabapentin in the treatment of trigeminal neuralgia: a systematic review of randomized controlled trials. J Investig Clin Dent. 2019;10(4):e12448. doi:10.1111/jicd.12448

103. Lemos L, Flores S, Oliveira P, Almeida A. Gabapentin supplemented with ropivacain block of trigger points improves pain control and quality of life in trigeminal neuralgia patients when compared with gabapentin alone. Clin J Pain. 2008;24(1):64-75. doi:10.1097/AJP.0b013e318158011a

104. Cheshire WP. Defining the role for gabapentin in the treatment of trigeminal neuralgia: a retrospective study. J Pain. 2002;3 (2):137-142. doi:10.1054/jpai.2002.122944

105. Fornasari D. Pharmacotherapy for neuropathic pain: a review. Pain Ther. 2017;6(Suppl 1):25-33. doi:10.1007/s40122-0170091-4

106. Hamasaki T, Yano S, Nakamura K, Yamada K. Pregabalin as a salvage preoperative treatment for refractory trigeminal neuralgia. $J$ Clin Neurosci. 2018;47:240-244. doi:10.1016/j. jocn.2017.10.039

107. Obermann M, Yoon MS, Sensen K, Maschke M, Diener HC, Katsarava Z. Efficacy of pregabalin in the treatment of trigeminal neuralgia. Cephalalgia. 2008;28(2):174-181. doi:10.1111/j.14682982.2007.01483.x

108. Court JE, Kase CS. Treatment of tic douloureux with a new anticonvulsant (clonazepam). J Neurol Neurosurg Psychiatry. 1976;39(3):297-299. doi:10.1136/jnnp.39.3.297

109. Peiris JB, Perera GL, Devendra SV, Lionel ND. Sodium valproate in trigeminal neuralgia. Med J Aust. 1980;2(5):278. doi:10.5694/ j.1326-5377.1980.tb131854.x

110. Reder AT, Arnason BG. Trigeminal neuralgia in multiple sclerosis relieved by a prostaglandin E analogue. Neurology. 1995;45 (6):1097-1100. doi:10.1212/WNL.45.6.1097

111. White T, Rastogi R, Singh TSS. Trigeminal neuralgia. In: AbdElsayed A, editor. Pain. Cham: Springer; 2019.

112. Kaplan M, Erol FS, Ozveren MF, Topsakal C, Sam B, Tekdemir I. Review of complications due to foramen ovale puncture. J Clin Neurosci. 2007;14(6):563-568. doi:10.1016/j.jocn.2005.11.043

113. Allam AE, Khalil AAF, Eltawab BA, Wu WT, Chang KV. Ultrasound-guided intervention for treatment of trigeminal neuralgia: an updated review of anatomy and techniques. Pain Res Manag. 2018;2018:5480728. doi:10.1155/2018/ 5480728

114. Nader A, Bendok BR, Prine JJ, Kendall MC. Ultrasound-guided pulsed radiofrequency application via the pterygopalatine fossa: a practical approach to treat refractory trigeminal neuralgia. Pain Physician. 2015;18(3):E411-415.

115. Nader A, Kendall MC, De Oliveria GS, et al. Ultrasound-guided trigeminal nerve block via the pterygopalatine fossa: an effective treatment for trigeminal neuralgia and atypical facial pain. Pain Physician. 2013;16(5):E537-545.

116. Spinner D, Kirschner JS. Accuracy of ultrasound-guided superficial trigeminal nerve blocks using methylene blue in cadavers. Pain Med. 2012;13(11):1469-1473. doi:10.1111/j.15264637.2012.01480.x 
117. Takechi K, Konishi A, Kikuchi K, et al. Real-time ultrasound-guided infraorbital nerve block to treat trigeminal neuralgia using a high concentration of tetracaine dissolved in bupivacaine. Scand J Pain. 2015;6(1):51-54. doi:10.1016/j. sjpain.2014.10.003

118. Tsui BC. Ultrasound imaging to localize foramina for superficial trigeminal nerve block. Can J Anaesth. 2009;56(9):704-706. doi:10.1007/s12630-009-9129-3

119. An JX, Liu H, Chen RW, et al. Computed tomography-guided percutaneous ozone injection of the Gasserian ganglion for the treatment of trigeminal neuralgia. J Pain Res. 2018;11:255-263. doi:10.2147/JPR.S140369

120. Gusmao S, Oliveira M, Tazinaffo U, Honey CR. Percutaneous trigeminal nerve radiofrequency rhizotomy guided by computerized tomography fluoroscopy. Technical note. J Neurosurg. 2003;99(4):785-786. doi:10.3171/jns.2003.99.4.0785

121. Horiguchi J, Ishifuro M, Fukuda H, Akiyama Y, Ito K. Multiplanar reformat and volume rendering of a multidetector CT scan for path planning a fluoroscopic procedure on Gasserian ganglion block-A preliminary report. Eur J Radiol. 2005;53(2):189-191. doi:10.1016/j.ejrad.2004.04.009

122. Koizuka S, Nakajima K, Mieda R. CT-guided nerve block: a review of the features of CT fluoroscopic guidance for nerve blocks. J Anesth. 2014;28(1):94-101. doi:10.1007/s00540-013-1675-8

123. Okuda Y, Okuda K, Shinohara M, Kitajima T. Use of computed tomography for maxillary nerve block in the treatment of trigeminal neuralgia. Reg Anesth Pain Med. 2000;25(4):417-419. doi:10.1053/rapm.2000.6447

124. Mullan S, Lichtor T. Percutaneous microcompression of the trigeminal ganglion for trigeminal neuralgia. J Neurosurg. 1983;59 (6):1007-1012. doi:10.3171/jns.1983.59.6.1007

125. Brown JA, Hoeflinger B, Long PB, et al. Axon and ganglion cell injury in rabbits after percutaneous trigeminal balloon compression. Neurosurgery. 1996;38(5):993-1003; discussion 1003-1004. doi:10.1097/00006123-199605000-00028

126. Skirving DJ, Dan NG. A 20-year review of percutaneous balloon compression of the trigeminal ganglion. J Neurosurg. 2001;94 (6):913-917. doi:10.3171/jns.2001.94.6.0913

127. Abdennebi B, Guenane L. Technical considerations and outcome assessment in retrogasserian balloon compression for treatment of trigeminal neuralgia. Series of 901 patients. Surg Neurol Int. 2014;5:118. doi:10.4103/2152-7806.137838

128. Asplund P, Blomstedt P, Bergenheim AT. Percutaneous balloon compression vs percutaneous retrogasserian glycerol rhizotomy for the primary treatment of trigeminal neuralgia. Neurosurgery. 2016;78(3):421-428; discussion 428. doi:10.1227/ NEU.0000000000001059

129. Brown JA, Pilitsis JG. Percutaneous balloon compression for the treatment of trigeminal neuralgia: results in 56 patients based on balloon compression pressure monitoring. Neurosurg Focus. 2005;18(5):E10. doi:10.3171/foc.2005.18.5.11

130. Cheng JS, Lim DA, Chang EF, Barbaro NM. A review of percutaneous treatments for trigeminal neuralgia. Neurosurgery. 2014;10(Suppl 1):25-33; discussion 33.

131. Kouzounias K, Lind G, Schechtmann G, Winter J, Linderoth B. Comparison of percutaneous balloon compression and glycerol rhizotomy for the treatment of trigeminal neuralgia. $J$ Neurosurg. 2010;113(3):486-492. doi:10.3171/2010.1.JNS091106

132. Lee ST, Chen JF. Percutaneous trigeminal ganglion balloon compression for treatment of trigeminal neuralgia, part II: results related to compression duration. Surg Neurol. 2003;60(2):149153;discussion 153-144. doi:10.1016/S0090-3019(03)00253-2

133. Lee ST, Chen JF. Percutaneous trigeminal ganglion balloon compression for treatment of trigeminal neuralgia-part I: pressure recordings. Surg Neurol. 2003;59(1):63-66; discussion 66-67. doi:10.1016/S0090-3019(02)00899-6
134. Martin S, Teo M, Suttner N. The effectiveness of percutaneous balloon compression in the treatment of trigeminal neuralgia in patients with multiple sclerosis. $J$ Neurosurg. 2015;123 (6):1507-1511. doi:10.3171/2014.11.JNS14736

135. Montano N, Conforti G, Di Bonaventura R, Meglio M, Fernandez E, Papacci F. Advances in diagnosis and treatment of trigeminal neuralgia. Ther Clin Risk Manag. 2015;11:289-299. doi: $10.2147 /$ TCRM.S37592

136. Montano N, Papacci F, Cioni B, Di Bonaventura R, Meglio M. The role of percutaneous balloon compression in the treatment of trigeminal neuralgia recurring after other surgical procedures. Acta Neurol Belg. 2014;114(1):59-64. doi:10.1007/s13760-0130263-x

137. Noorani I, Lodge A, Vajramani G, Sparrow O. Comparing percutaneous treatments of trigeminal neuralgia: 19 years of experience in a single centre. Stereotact Funct Neurosurg. 2016;94(2):75-85. doi:10.1159/000445077

138. Wang JY, Bender MT, Bettegowda C. Percutaneous procedures for the treatment of trigeminal neuralgia. Neurosurg Clin $\mathrm{N} \mathrm{Am}$. 2016;27(3):277-295. doi:10.1016/j.nec.2016.02.005

139. Asplund P, Linderoth B, Bergenheim AT. The predictive power of balloon shape and change of sensory functions on outcome of percutaneous balloon compression for trigeminal neuralgia. $J \quad$ Neurosurg. 2010;113(3):498-507. doi:10.3171/2010.2. JNS091466

140. Tibano AT, de Siqueira SR, da Nobrega JC, Teixeira MJ. Cardiovascular response during trigeminal ganglion compression for trigeminal neuralgia according to the use of local anesthetics. Acta Neurochir (Wien). 2010;152(8):1347-1351. doi:10.1007/ s00701-010-0664-z

141. Kefalopoulou Z, Markaki E, Constantoyannis C. Avoiding abducens nerve palsy during the percutaneous balloon compression procedure. Stereotact Funct Neurosurg. 2009;87(2):101-104. doi:10.1159/000202976

142. Harris W. Three cases of alcohol injection of the gasserian ganglion for trigeminal neuralgia. Proc $R$ Soc Med. 1912;5 (ClinSect):115-119.

143. Bick SKB, Eskandar EN. Surgical treatment of trigeminal neuralgia. Neurosurg Clin N Am. 2017;28(3):429-438. doi:10.1016/j.nec.2017.02.009

144. Eide PK, Stubhaug A. Relief of trigeminal neuralgia after percutaneous retrogasserian glycerol rhizolysis is dependent on normalization of abnormal temporal summation of pain, without general impairment of sensory perception. Neurosurgery. 1998;43 (3):462-472; discussion 472-464. doi:10.1097/00006123199809000-00036

145. Han KR, Chae YJ, Lee JD, Kim C. Trigeminal nerve block with alcohol for medically intractable classic trigeminal neuralgia: long-term clinical effectiveness on pain. Int J Med Sci. 2017;14 (1):29-36. doi:10.7150/ijms.16964

146. Shah SA, Khan MN, Shah SF, Ghafoor A, Khattak A. Is peripheral alcohol injection of value in the treatment of trigeminal neuralgia? An analysis of 100 cases. Int J Oral Maxillofac Surg. 2011;40(4):388-392. doi:10.1016/j.ijom.2010.11.010

147. McLeod NM, Patton DW. Peripheral alcohol injections in the management of trigeminal neuralgia. Oral Surg Oral Med Oral Pathol Oral Radiol Endod. 2007;104(1):12-17. doi:10.1016/j. tripleo.2007.01.001

148. Nathan PW, Sears TA, Smith MC. Effects of phenol solutions on the nerve roots of the cat: an electrophysiological and histological study. J Neurol Sci. 1965;2(1):7-29. doi:10.1016/0022-510X(65) 90060-2

149. Westerlund T, Vuorinen V, Roytta M. The effect of combined neurolytic blocking agent $5 \%$ phenol-glycerol in rat sciatic nerve. Acta Neuropathol. 2003;106(3):261-270. doi:10.1007/s00401003-0730-1 
150. Nathan PW. Intrathecal phenol to relieve spasticity in paraplegia. Lancet. 1959;2(7112):1099-1102. doi:10.1016/S0140-6736(59) 90094-7

151. Zafonte RD, Munin MC. Phenol and alcohol blocks for the treatment of spasticity. Phys Med Rehabil Clin N Am. 2001;12 (4):817-832, vii. doi:10.1016/S1047-9651(18)30034-2

152. Jefferson A. Trigeminal root and ganglion injections using phenol in glycerine for the relief of trigeminal neuralgia. J Neurol Neurosurg Psychiatry. 1963;26:345-352. doi:10.1136/jnnp.26.4.345

153. Wilkinson HA. Trigeminal nerve peripheral branch phenol/glycerol injections for tic douloureux. $J$ Neurosurg. 1999;90 (5):828-832. doi:10.3171/jns.1999.90.5.0828

154. Kirvela O, Svedstrom E, Lundbom N. Ultrasonic guidance of lumbar sympathetic and celiac plexus block: a new technique. Reg Anesth. 1992;17(1):43-46.

155. Maher RM. Relief of pain in incurable cancer. Lancet. 1955;268 (6853):18-20. doi:10.1016/S0140-6736(55)93213-X

156. Lunsford LD, Bennett MH, Martinez AJ. Experimental trigeminal glycerol injection. Electrophysiologic and morphologic effects. Arch Neurol. 1985;42(2):146-149. doi:10.1001/archneur.1985.04060 020060016

157. Dulhunty AF, Gage PW. Differential effects of glycerol treatment on membrane capacity and excitation-contraction coupling in toad sartorius fibres. $J$ Physiol. 1973;234(2):373-408. doi:10.1113/ jphysiol.1973.sp010350

158. Xu-Hui W, Chun Z, Guang-Jian S, et al. Long-term outcomes of percutaneous retrogasserian glycerol rhizotomy in 3370 patients with trigeminal neuralgia. Turk Neurosurg. 2011;21(1):48-52.

159. Bergenheim AT, Hariz MI. Influence of previous treatment on outcome after glycerol rhizotomy for trigeminal neuralgia Neurosurgery. 1995;36(2):303-309; discussion 309-310. doi:10.1227/00006123-199502000-00009

160. Bergenheim AT, Hariz MI, Laitinen LV, Olivecrona M, Rabow L. Relation between sensory disturbance and outcome after retrogasserian glycerol rhizotomy. Acta Neurochir (Wien). 1991;111 (3-4):114-118. doi:10.1007/BF01400498

161. Eide PK, Stubhaug A. Sensory perception in patients with trigeminal neuralgia: effects of percutaneous retrogasserian glycerol rhizotomy. Stereotact Funct Neurosurg. 1997;68(1-4Pt 1):207-211. doi:10.1159/000099925

162. Hakanson S. Trigeminal neuralgia treated by the injection of glycerol into the trigeminal cistern. Neurosurgery. 1981;9 (6):638-646. doi:10.1227/00006123-198112000-00005

163. Jho HD, Lunsford LD. Percutaneous retrogasserian glycerol rhizotomy. Current technique and results. Neurosurg Clin N Am. 1997;8(1):63-74. doi:10.1016/S1042-3680(18)30338-3

164. North RB, Kidd DH, Piantadosi S, Carson BS. Percutaneous retrogasserian glycerol rhizotomy. Predictors of success and failure in treatment of trigeminal neuralgia. $J$ Neurosurg. 1990;72 (6):851-856. doi:10.3171/jns.1990.72.6.0851

165. Sindou M, Tatli M. Traitement de la névralgie trigéminale par injection de glycérol au niveau du ganglion de Gasser. Neurochirurgie. 2009;55(2):211-212. doi:10.1016/j.neuchi.2009.01.009

166. Sweet WH, Wepsic JG. Controlled thermocoagulation of trigeminal ganglion and rootlets for differential destruction of pain fibers. 1. Trigeminal neuralgia. $J$ Neurosurg. 1974;40 (2):143-156. doi:10.3171/jns.1974.40.2.0143

167. Wu CY, Meng FG, Xu SJ, Liu YG, Wang HW. Selective percutaneous radiofrequency thermocoagulation in the treatment of trigeminal neuralgia: report on 1860 cases. Chin Med J (Engl). 2004;117(3):467-470. doi:10.1142/S0192415X04002120

168. Kanpolat Y, Savas A, Bekar A, Berk C. Percutaneous controlled radiofrequency trigeminal rhizotomy for the treatment of idiopathic trigeminal neuralgia: 25-year experience with 1600 patients. Neurosurgery. 2001;48(3):524-532; discussion 532-524. doi:10.1097/00006123-200103000-00013
169. Abdel-Rahman KA, Elawamy AM, Mostafa MF, et al. Combined pulsed and thermal radiofrequency versus thermal radiofrequency alone in the treatment of recurrent trigeminal neuralgia after microvascular decompression: a double blinded comparative study. Eur J Pain. 2020;24(2):338-345. doi:10.1002/ejp.1489

170. Akbas M, Salem HH, Emara TH, Dinc B, Karsli B. Radiofrequency thermocoagulation in cases of atypical trigeminal neuralgia: a retrospective study. Egypt J Neurol Psychiatry Neurosurg. 2019;55:46. doi:10.1186/s41983-019-0092-9

171. Burchiel KJ, Steege TD, Howe JF, Loeser JD. Comparison of percutaneous radiofrequency gangliolysis and microvascular decompression for the surgical management of tic douloureux. Neurosurgery. 1981;9(2):111-119. doi:10.1227/00006123198108000-00001

172. Ding Y, Li H, Hong T, Zhu Y, Yao P, Zhou G. Combination of pulsed radiofrequency with continuous radiofrequency thermocoagulation at low temperature improves efficacy and safety in V2/V3 primary trigeminal neuralgia. Pain Phys. 2018;21(5):E545-E553.

173. Elawamy A, Abdalla EE, Shehata GA. Effects of pulsed versus conventional versus combined radiofrequency for the treatment of trigeminal neuralgia: a prospective study. Pain Phys. 2017;20(6): E873-E881.

174. Emril DR, Ho KY. Treatment of trigeminal neuralgia: role of radiofrequency ablation. J Pain Res. 2010;3:249-254.

175. Sanchez-Mejia RO, Limbo M, Cheng JS, Camara J, Ward MM, Barbaro NM. Recurrent or refractory trigeminal neuralgia after microvascular decompression, radiofrequency ablation, or radiosurgery. Neurosurg Focus. 2005;18(5):e12. doi:10.3171/ foc.2005.18.5.13

176. Thapa D, Ahuja V, Dass C, Verma P. Management of refractory trigeminal neuralgia using extended duration pulsed radiofrequency application. Pain Physician. 2015;18(3):E433-E435.

177. Tronnier VM, Rasche D, Hamer J, Kienle AL, Kunze S. Treatment of idiopathic trigeminal neuralgia: comparison of long-term outcome after radiofrequency rhizotomy and microvascular decompression. Neurosurgery. 2001;48(6):1261-1267;discussion 1267-1268.

178. Xu SJ, Zhang WH, Chen T, Wu CY, Zhou MD. Neuronavigatorguided percutaneous radiofrequency thermocoagulation in the treatment of intractable trigeminal neuralgia. Chin Med J (Engl). 2006;119 (18):1528-1535. doi:10.1097/00029330-200609020-00005

179. Zakrzewska JM, Jassim S, Bulman SJ. A prospective, longitudinal study on patients with trigeminal neuralgia who underwent radiofrequency thermocoagulation of the Gasserian ganglion. Pain. 1999;79(1):51-58. doi:10.1016/S0304-3959(98)00145-6

180. Yoon KB, Wiles JR, Miles JB, Nurmikko TJ. Long-term outcome of percutaneous thermocoagulation for trigeminal neuralgia. Anaesthesia. 1999;54(8):803-808. doi:10.1046/j.13652044.1999.00905.x

181. Bender MT, Pradilla G, Batra S, et al. Glycerol rhizotomy and radiofrequency thermocoagulation for trigeminal neuralgia in multiple sclerosis. $J$ Neurosurg. 2013;118(2):329-336. doi:10.3171/2012.9.JNS1226

182. Lloyd JW, Barnard JD, Glynn CJ. Cryoanalgesia. A new approach to pain relief. Lancet. 1976;2(7992):932-934. doi:10.1016/S0140-6736(76)90893-X

183. Zakrzewska JM. Cryotherapy in the management of paroxysmal trigeminal neuralgia. J Neurol Neurosurg Psychiatry. 1987;50 (4):485-487. doi:10.1136/jnnp.50.4.485

184. Zakrzewska JM. Cryotherapy for trigeminal neuralgia: a 10 year audit. Br J Oral Maxillofac Surg. 1991;29(1):1-4. doi:10.1016/ 0266-4356(91)90162-X

185. Zakrzewska JM, Nally FF. The role of cryotherapy (cryoanalgesia) in the management of paroxysmal trigeminal neuralgia: a six year experience. Br J Oral Maxillofac Surg. 1988;26 (1):18-25. doi:10.1016/0266-4356(88)90145-3 
186. Pradel W, Hlawitschka M, Eckelt U, Herzog R, Koch K. Cryosurgical treatment of genuine trigeminal neuralgia. $\mathrm{Br} \mathrm{J} \mathrm{Oral}$ Maxillofac Surg. 2002;40(3):244-247. doi:10.1054/bjom.2001.0765

187. Nally FF. A 22-year study of paroxysmal trigeminal neuralgia in 211 patients with a 3-year appraisal of the role of cryotherapy. Oral Surg Oral Med Oral Pathol. 1984;58(1):17-23. doi:10.1016/ 0030-4220(84)90357-8

188. Politis C, Adriaensen H, Bossuyt M, Fossion E. The management of trigeminal neuralgia with cryotherapy. Acta Stomatol Belg. 1988;85(3):197-205.

189. Chang KV, Lin CS, Lin CP, Wu WT, Ozcakar L. Recognition of the lateral pterygoid muscle and plate during ultrasound-guided trigeminal nerve block. J Clin Diagn Res. 2017;11(5):UL01-UL02.

190. Di Stani F, Ojango C, Dugoni D, et al. Combination of pharmacotherapy and lidocaine analgesic block of the peripheral trigeminal branches for trigeminal neuralgia: a pilot study. Arq Neuropsiquiatr. 2015;73(8):660-664. doi:10.1590/0004-282X20150077

191. Goto F, Ishizaki K, Yoshikawa D, Obata H, Arii H, Terada M. The long lasting effects of peripheral nerve blocks for trigeminal neuralgia using high concentration of tetracaine dissolved in bupivacaine. Pain. 1999;79(1):101-103. doi:10.1016/S03043959(98)00156-0

192. Radwan IA, Saito S, Goto F. High-concentration tetracaine for the management of trigeminal neuralgia: quantitative assessment of sensory function after peripheral nerve block. Clin J Pain. 2001;17(4):323-326. doi:10.1097/00002508-200112000-00006

193. Han KR, Kim C, Chae YJ, Kim DW. Efficacy and safety of high concentration lidocaine for trigeminal nerve block in patients with trigeminal neuralgia. Int J Clin Pract. 2008;62(2):248-254. doi:10.1111/j.1742-1241.2007.01568.x

194. Guardiani E, Sadoughi B, Blitzer A, Sirois D. A new treatment paradigm for trigeminal neuralgia using Botulinum toxin type A. Laryngoscope. 2014;124(2):413-417. doi:10.1002/lary.24286

195. Liu J, Xu YY, Zhang QL, Luo WF. Efficacy and safety of botulinum toxin type $\mathrm{A}$ in treating patients of advanced age with idiopathic trigeminal neuralgia. Pain Res Manag. 2018;2018:7365148. doi:10.1155/2018/7365148

196. Morra ME, Elgebaly A, Elmaraezy A, et al. Therapeutic efficacy and safety of Botulinum Toxin A therapy in Trigeminal Neuralgia: a systematic review and meta-analysis of randomized controlled trials. J Headache Pain. 2016;17(1):63. doi:10.1186/ s10194-016-0651-8

197. Park J, Park HJ. Botulinum toxin for the treatment of neuropathic pain. Toxins (Basel). 2017;9(9). doi:10.3390/toxins9090260

198. Shehata HS, El-Tamawy MS, Shalaby NM, Ramzy G. Botulinum toxin-type A: could it be an effective treatment option in intractable trigeminal neuralgia? J Headache Pain. 2013;14:92. doi:10.1186/1129-2377-14-92

199. Wu CJ, Lian YJ, Zheng YK, et al. Botulinum toxin type A for the treatment of trigeminal neuralgia: results from a randomized, double-blind, placebo-controlled trial. Cephalalgia. 2012;32 (6):443-450. doi:10.1177/0333102412441721

200. Zhang H, Lian Y, Ma Y, et al. Two doses of botulinum toxin type A for the treatment of trigeminal neuralgia: observation of therapeutic effect from a randomized, double-blind, placebo-controlled trial. $J$ Headache Pain. 2014;15:65. doi:10.1186/1129-2377-15-65

201. Zuniga C, Piedimonte F, Diaz S, Micheli F. Acute treatment of trigeminal neuralgia with onabotulinum toxin A. Clin Neuropharmacol. 2013;36(5):146-150. doi:10.1097/ WNF.0b013e31829cb60e

202. Lucioni A, Bales GT, Lotan TL, McGehee DS, Cook SP, Rapp DE. Botulinum toxin type A inhibits sensory neuropeptide release in rat bladder models of acute injury and chronic inflammation. BJU Int. 2008;101(3):366-370. doi:10.1111/ j.1464-410X.2007.07312.x
203. Nugent M, Yusef YR, Meng J, Wang J, Dolly JO. A SNAP-25 cleaving chimera of botulinum neurotoxin /A and /E prevents TNFalpha-induced elevation of the activities of native TRP channels on early postnatal rat dorsal root ganglion neurons. Neuropharmacology. 2018;138:257-266. doi:10.1016/j. neuropharm.2018.06.016

204. Piovesan EJ, Teive HG, Kowacs PA, Della Coletta MV, Werneck LC, Silberstein SD. An open study of botulinum-A toxin treatment of trigeminal neuralgia. Neurology. 2005;65(8):1306-1308. doi:10.1212/01. wnl.0000180940.98815.74

205. Turk Boru U, Duman A, Boluk C, Coskun duman S, Tasdemir M. Botulinum toxin in the treatment of trigeminal neuralgia: 6-Month follow-up. Medicine (Baltimore). 2017;96(39):e8133. doi:10.1097/Md.0000000000008133

206. Spina A, Brugliera L, Gagliardi F, et al. A reappraisal on botulinum toxin-A in trigeminal neuralgia. J Neurosurg Sci. 2020. doi:10.23736/S0390-5616.20.05125-5

207. Wall PD, Sweet WH. Temporary abolition of pain in man. Science. 1967;155(3758):108-109. doi:10.1126/ science. 155.3758 .108

208. Slavin KV. Neuromodulation for facial pain. In: Progress in Neurological Surgery. Basel; Hartford: Karger; 2020.

209. Yameen F, Shahbaz NN, Hasan Y, Fauz R, Abdullah M. Efficacy of transcutaneous electrical nerve stimulation and its different modes in patients with trigeminal neuralgia. J Pak Med Assoc. 2011;61(5):437-439.

210. Singla S, Prabhakar V, Singla RK. Role of transcutaneous electric nerve stimulation in the management of trigeminal neuralgia. J Neurosci Rural Pract. 2011;2(2):150-152. doi:10.4103/09763147.83580

211. Shelden CH, Pudenz RH, Doyle J. Electrical control of facial pain. Am J Surg. 1967;114(2):209-212. doi:10.1016/00029610(67)90374-1

212. Meyerson BA, Hakansson S. Alleviation of atypical trigeminal pain by stimulation of the Gasserian ganglion via an implanted electrode. Acta Neurochir Suppl (Wien). 1980;30:303-309.

213. Ellis JA, Mejia Munne JC, Winfree CJ. Trigeminal branch stimulation for the treatment of intractable craniofacial pain. $J \quad$ Neurosurg. 2015;123(1):283-288. doi:10.3171/2014.12. JNS14645

214. Coffey RJ. Deep brain stimulation for chronic pain: results of two multicenter trials and a structured review. Pain Med. 2001;2 (3):183-192. doi:10.1046/j.1526-4637.2001.01029.x

215. Nandi D, Aziz T, Carter H, Stein J. Thalamic field potentials in chronic central pain treated by periventricular gray stimulation a series of eight cases. Pain. 2003;101(1-2):97-107. doi:10.1016/ S0304-3959(02)00277-4

216. Franzini A, Messina G, Cordella R, Marras C, Broggi G. Deep brain stimulation of the posteromedial hypothalamus: indications, long-term results, and neurophysiological considerations. Neurosurg Focus. 2010;29(2):E13. doi:10.3171/2010.5. FOCUS1094

217. Martin E, Jeanmonod D, Morel A, Zadicario E, Werner B. Highintensity focused ultrasound for noninvasive functional neurosurgery. Ann Neurol. 2009;66(6):858-861. doi:10.1002/ ana. 21801

218. Monteith SJ, Medel R, Kassell NF, et al. Transcranial magnetic resonance-guided focused ultrasound surgery for trigeminal neuralgia: a cadaveric and laboratory feasibility study. J Neurosurg. 2013;118(2):319-328. doi:10.3171/2012.10.JNS12186

219. Fontaine D, Hamani C, Lozano A. Efficacy and safety of motor cortex stimulation for chronic neuropathic pain: critical review of the literature. J Neurosurg. 2009;110(2):251-256. doi:10.3171/ 2008.6.17602 
220. Henssen D, Kurt E, van Cappellen van Walsum AM, et al. Longterm effect of motor cortex stimulation in patients suffering from chronic neuropathic pain: an observational study. PLoS One. 2018;13(1):e0191774. doi:10.1371/journal.pone.0191774

221. Lefaucheur JP, Drouot X, Menard-Lefaucheur I, et al. Neurogenic pain relief by repetitive transcranial magnetic cortical stimulation depends on the origin and the site of pain. $J$ Neurol Neurosurg Psychiatry. 2004;75(4):612-616. doi:10.1136/jnnp.2003.022236

222. Khedr EM, Kotb H, Kamel NF, Ahmed MA, Sadek R, Rothwell JC. Longlasting antalgic effects of daily sessions of repetitive transcranial magnetic stimulation in central and peripheral neuropathic pain. J Neurol Neurosurg Psychiatry. 2005;76 (6):833-838. doi:10.1136/jnnp.2004.055806

223. Leksell L. Sterotaxic radiosurgery in trigeminal neuralgia. Acta Chir Scand. 1971;137(4):311-314.

224. Leksell L. Stereotactic radiosurgery. J Neurol Neurosurg Psychiatry. 1983;46(9):797-803. doi:10.1136/jnnp.46.9.797

225. Matsuda S, Serizawa T, Sato M, Ono J. Gamma knife radiosurgery for trigeminal neuralgia: the dry-eye complication. $J$ Neurosurg. 2002;97(5 Suppl):525-528. doi:10.3171/ jns.2002.97.supplement_5.0525

226. Mendelson ZS, Velagala JR, Kohli G, Heir GM, Mammis A, Liu JK. Pain-free outcomes and durability of surgical intervention for trigeminal neuralgia: a comparison of gamma knife and microvascular decompression. World Neurosurg. 2018;112: e732-e746. doi:10.1016/j.wneu.2018.01.141

227. Park SH, Hwang SK, Kang DH, Park J, Hwang JH, Sung JK. The retrogasserian zone versus dorsal root entry zone: comparison of two targeting techniques of gamma knife radiosurgery for trigeminal neuralgia. Acta Neurochir (Wien). 2010;152(7):1165-1170. doi:10.1007/s00701-010-0610-0

228. Deinsberger R, Tidstrand J. Linac radiosurgery as a tool in neurosurgery. Neurosurg Rev. 2005;28(2):79-88; discussion 8990, 91. doi:10.1007/s10143-005-0376-7

229. Smith ZA, Gorgulho AA, Bezrukiy N, et al. Dedicated linear accelerator radiosurgery for trigeminal neuralgia: a single-center experience in 179 patients with varied dose prescriptions and treatment plans. Int $J$ Radiat Oncol Biol Phys. 2011;81 (1):225-231. doi:10.1016/j.ijrobp.2010.05.058

230. Tuleasca C, Regis J, Sahgal A, et al. Stereotactic radiosurgery for trigeminal neuralgia: a systematic review. J Neurosurg. 2018;130 (3):733-757. doi:10.3171/2017.9.JNS17545

231. Flickinger JC, Pollock BE, Kondziolka D, et al. Does increased nerve length within the treatment volume improve trigeminal neuralgia radiosurgery? A prospective double-blind, randomized study. Int J Radiat Oncol Biol Phys. 2001;51(2):449-454. doi:10.1016/S0360-3016(01)01606-6

232. Alberico RA, Fenstermaker RA, Lobel J. Focal enhancement of cranial nerve $\mathrm{V}$ after radiosurgery with the Leksell gamma knife: experience in 15 patients with medically refractory trigeminal neuralgia. AJNR Am J Neuroradiol. 2001;22(10):1944-1948.

233. Dominguez L, Saway B, Benko MJ, Guilliams E, Marvin EA, Entwistle JJ. Ruptured distal superior cerebellar artery aneurysm after gamma knife radiosurgery for trigeminal neuralgia: a case report and review of the literature. World Neurosurg. 2020;135:2-6. doi:10.1016/j.wneu.2019.10.136

234. Goss BW, Frighetto L, DeSalles AA, Smith Z, Solberg T, Selch M. Linear accelerator radiosurgery using 90 gray for essential trigeminal neuralgia: results and dose volume histogram analysis. Neurosurgery. 2003;53(4):823-828; discussion 828830. doi:10.1227/01.NEU.0000083550.03928.D8

235. Han JH, Kim DG, Chung HT, et al. Long-term outcome of gamma knife radiosurgery for treatment of typical trigeminal neuralgia. Int J Radiat Oncol Biol Phys. 2009;75(3):822-827. doi:10.1016/j.ijrobp.2008.11.046
236. Herman JM, Petit JH, Amin P, Kwok Y, Dutta PR, Chin LS. Repeat gamma knife radiosurgery for refractory or recurrent trigeminal neuralgia: treatment outcomes and quality-of-life assessment. Int J Radiat Oncol Biol Phys. 2004;59(1):112-116. doi:10.1016/j.ijrobp.2003.10.041

237. Kondziolka D, Lunsford LD, Flickinger JC, et al. Stereotactic radiosurgery for trigeminal neuralgia: a multiinstitutional study using the gamma unit. $J$ Neurosurg. 1996;84(6):940-945. doi:10.3171/jns.1996.84.6.0940

238. Kondziolka D, Perez B, Flickinger JC, Habeck M, Lunsford LD. Gamma knife radiosurgery for trigeminal neuralgia: results and expectations. Arch Neurol. 1998;55(12):1524-1529. doi:10.1001/ archneur.55.12.1524

239. Kondziolka D, Zorro O, Lobato-Polo J, et al. Gamma knife stereotactic radiosurgery for idiopathic trigeminal neuralgia. $J \quad$ Neurosurg. 2010;112(4):758-765. doi:10.3171/2009.7. JNS09694

240. Little AS, Shetter AG, Shetter ME, Kakarla UK, Rogers CL. Salvage gamma knife stereotactic radiosurgery for surgically refractory trigeminal neuralgia. Int J Radiat Oncol Biol Phys. 2009;74(2):522-527. doi:10.1016/j.ijrobp.2008.08.048

241. Massager N, Abeloos L, Devriendt D, Op de Beeck M, Levivier M. Clinical evaluation of targeting accuracy of gamma knife radiosurgery in trigeminal neuralgia. Int J Radiat Oncol Biol Phys. 2007;69(5):1514-1520. doi:10.1016/j.ijrobp.2007.05.013

242. Petit JH, Herman JM, Nagda S, DiBiase SJ, Chin LS. Radiosurgical treatment of trigeminal neuralgia: evaluating quality of life and treatment outcomes. Int J Radiat Oncol Biol Phys. 2003;56(4):1147-1153. doi:10.1016/S0360-3016(03)00264-5

243. Regis J, Tuleasca C, Resseguier N, et al. The very long-term outcome of radiosurgery for classical trigeminal neuralgia. Stereotact Funct Neurosurg. 2016;94(1):24-32. doi:10.1159/ 000443529

244. Richards GM, Bradley KA, Tome WA, Bentzen SM, Resnick DK, Mehta MP. Linear accelerator radiosurgery for trigeminal neuralgia. Neurosurgery. 2005;57(6):1193-1200. doi:10.1227/01. NEU.0000186015.01179.70

245. Sharma R, Phalak M, Katiyar V, Borkar S, Kale SS, Mahapatra AK. Microvascular decompression versus stereotactic radiosurgery as primary treatment modality for trigeminal neuralgia: a systematic review and meta-analysis of prospective comparative trials. Neurol India. 2018;66(3):688-694. doi:10.4103/ 0028-3886.232342

246. Spina A, Mortini P, Alemanno F, Houdayer E, Iannaccone S. Trigeminal neuralgia: toward a multimodal approach. World Neurosurg. 2017;103:220-230. doi:10.1016/j.wneu.2017.03.126

247. Spina A, Boari N, Gagliardi F, Bailo M, Iannaccone S, Mortini P. Gamma knife radiosurgery for trigeminal neuralgia: when? Neurosurg Rev. 2019;42(2):599-601. doi:10.1007/s10143-01901099-z

248. Spina A, Boari N, Mortini P. Letter to the Editor. Earlier radiosurgery is related to better outcome in trigeminal neuralgia. $J$ Neurosurg. 2020;1-2. doi:10.3171/2020.9.JNS203342

249. Tan TC, Black PM. Sir Victor Horsley (1857-1916): pioneer of neurological surgery. Neurosurgery. 2002;50(3):607-611;discussion 611-602.

250. Dandy WE. An operation for the cure of Tic Douloureux. Arch Surg. 1929;18(2):687. doi:10.1001/ archsurg.1929.04420030081005

251. Dandy WE. The treatment of trigeminal neuralgia by the cerebellar route. Ann Surg. 1932;96(4):787-795. doi:10.1097/00000658193210000-00026

252. Kaufmann AM, Price AV. A history of the Jannetta procedure. $J \quad$ Neurosurg. 2019;132(2):639-646. doi:10.3171/2018.10. JNS181983 
253. Pressman E, Jha RT, Zavadskiy G, et al. Teflon or Ivalon(R): a scoping review of implants used in microvascular decompression for trigeminal neuralgia. Neurosurg Rev. 2020;43(1):79-86. doi:10.1007/s10143-019-01187-0

254. Liu J, Chen Z, Feng T, Jiang B, Yuan Y, Yu Y. Biomedical glue sling technique in microvascular decompression for trigeminal neuralgia caused by atherosclerotic vertebrobasilar artery: a description of operative technique and clinical outcomes. World Neurosurg. 2019;128:e74-e80. doi:10.1016/j. wneu.2019.03.289

255. Steinberg JA, Sack J, Wilson B, et al. Tentorial sling for microvascular decompression in patients with trigeminal neuralgia: a description of operative technique and clinical outcomes. J Neurosurg. 2018;1-6. doi:10.3171/2017.10.JNS17971

256. Barker FG, Jannetta PJ, Bissonette DJ, Larkins MV, Jho HD. The long-term outcome of microvascular decompression for trigeminal neurlagia. $N$ Engl $J$ Med. 1996;334(17):1077-1083. doi:10.1056/NEJM199604253341701

257. Jannetta PJ, McLaughlin MR, Casey KF. Technique of microvascular decompression. Technical note. Neurosurg Focus. 2005;18 (5):E5. doi:10.3171/foc.2005.18.5.6

258. Sabourin V, Mazza J, Garzon T, et al. Internal neurolysis with and without microvascular decompression for trigeminal neuralgia: case series. World Neurosurg. 2020;143:e70-e77. doi:10.1016/j. wneu.2020.06.206

259. Sekula RF, Frederickson AM, Jannetta PJ, Quigley MR, Aziz KM, Arnone GD. Microvascular decompression for elderly patients with trigeminal neuralgia: a prospective study and systematic review with meta-analysis. J Neurosurg. 2011;114 (1):172-179. doi:10.3171/2010.6.JNS10142

260. Thirumala P, Meigh K, Dasyam N, et al. The incidence of high-frequency hearing loss after microvascular decompression for trigeminal neuralgia, glossopharyngeal neuralgia, or geniculate neuralgia. $J$ Neurosurg. 2015;123(6):1500-1506. doi:10.3171/2014.10.JNS141101

261. Tomasello F, Esposito F, Abbritti RV, et al. Microvascular decompression for trigeminal neuralgia: technical refinement for complication avoidance. World Neurosurg. 2016;94:26-31. doi:10.1016/j.wneu.2016.06.097

262. Zakrzewska JM, Coakham HB. Microvascular decompression for trigeminal neuralgia: update. Curr Opin Neurol. 2012;25 (3):296-301. doi:10.1097/WCO.0b013e328352c465

263. Zakrzewska JM, Lopez BC, Kim SE, Coakham HB. Patient reports of satisfaction after microvascular decompression and partial sensory rhizotomy for trigeminal neuralgia. Neurosurgery. 2005;56(6):1304-1311; discussion 1311-1302. doi:10.1227/01.NEU.0000159883.35957.E0

264. Obermann M. Treatment options in trigeminal neuralgia. Ther Adv Neurol Disord. 2010;3(2):107-115. doi:10.1177/ 1756285609359317

265. Holste K, Chan AY, Rolston JD, Englot DJ. Pain outcomes following microvascular decompression for drug-resistant trigeminal neuralgia: a systematic review and meta-analysis. Neurosurgery. 2020;86(2):182-190. doi:10.1093/neuros/nyz075

266. Radtke RA, Erwin CW, Wilkins RH. Intraoperative brainstem auditory evoked potentials: significant decrease in postoperative morbidity. Neurology. 1989;39(2 Pt 1):187-191. doi:10.1212/ WNL.39.2.187

267. Sindou M, Fobe JL, Ciriano D, Fischer C. Hearing prognosis and intraoperative guidance of brainstem auditory evoked potential in microvascular decompression. Laryngoscope. 1992;102 (6):678-682. doi:10.1288/00005537-199206000-00014

268. Narayan V, Savardekar AR, Patra DP, et al. Safety profile of superior petrosal vein (the vein of Dandy) sacrifice in neurosurgical procedures: a systematic review. Neurosurg Focus. 2018;45 (1):E3. doi:10.3171/2018.4.FOCUS18133
269. Pollock BE, Stien KJ. Posterior fossa exploration for trigeminal neuralgia patients older than 70 years of age. Neurosurgery. 2011;69(6):1255-1259;discussion 1259-1260. doi:10.1227/ NEU.0b013e31822ba315

270. Lee JH, Lee JM, Choi CH. Personal experience with microvascular decompression and partial sensory rhizotomy for trigeminal neuralgia. Yeungnam Univ J Med. 2020. doi:10.12701/ yujm.2020.00745

271. Liu R, Deng Z, Zhang L, Liu Y, Wang Z, Yu Y. The long-term outcomes and predictors of microvascular decompression with or without partial sensory rhizotomy for trigeminal neuralgia. J Pain Res. 2020;13:301-312. doi:10.2147/JPR.S225188

272. Liu Y, Yu Y, Wang Z, et al. Value of partial sensory rhizotomy in the microsurgical treatment of trigeminal neuralgia through retrosigmoid approach. J Pain Res. 2020;13:3207-3215. doi:10.2147/ JPR.S279674

273. Durnford AJ, Gaastra B, Akarca D, et al. Internal neurolysis: 'nerve combing' for trigeminal neuralgia without neurovascular conflict - early UK outcomes. Br J Neurosurg. 2020;1-4. doi:10.1080/02688697.2020.1837730

274. Ko AL, Ozpinar A, Lee A, Raslan AM, McCartney S, Burchiel KJ. Long-term efficacy and safety of internal neurolysis for trigeminal neuralgia without neurovascular compression. $J$ Neurosurg. 2015;122(5):1048-1057. doi:10.3171/2014.12. JNS14469

275. Kim TY, Jackson CM, Xia Y, et al. Retrosigmoid approach for glycerin rhizotomy in the treatment of trigeminal neuralgia without overt arterial compression: updated case series. J Neurosurg. 2019;132(4):1227-1233. doi:10.3171/2018.12.JNS182572

276. Agrawal SM, Kambalimath DH. Peripheral neurectomy: a minimally invasive treatment for trigeminal neuralgia. A retrospective study. J Maxillofac Oral Surg. 2011;10 (3):195-198. doi:10.1007/s12663-011-0229-6

277. Ali FM, Prasant M, Pai D, Aher VA, Kar S, Safiya T. Peripheral neurectomies: a treatment option for trigeminal neuralgia in rural practice. $J$ Neurosci Rural Pract. 2012;3(2):152-157. doi:10.4103/0976-3147.98218

278. Freemont AJ, Millac P. The place of peripheral neurectomy in the management of trigeminal neuralgia. Postgrad Med J. 1981;57 (664):75-76. doi:10.1136/pgmj.57.664.75

279. Kumar P, Maleedi S, Goud SS. Peripheral neurectomy: a surgical option for trigeminal neuralgia involving inferior alveolar nerve. $J$ Headache Pain Manag. 2017;02(02). doi:10.4172/24721913.100040

280. Lamichhane NS, Du X, Li S, Poudel DC. Effectiveness of peripheral neurectomy in refractory cases of trigeminal neuralgia. J Orofac Sci. 2016;8(2):86-91. doi:10.4103/0975-8844.195908

281. Yuvaraj V, Krishnan B, Therese BA, Balaji TS. Efficacy of neurectomy of peripheral branches of the trigeminal nerve in trigeminal neuralgia: a critical review of the literature. J Maxillofac Oral Surg. 2019;18(1):15-22. doi:10.1007/s12663018-1108-1

282. Zhu S, Rong Q, Chen S, Li X. Pterygopalatine fossa segment neurectomy of maxillary nerve through maxillary sinus route in treating trigeminal neuralgia. J Craniomaxillofac Surg. 2013;41 (7):652-656. doi:10.1016/j.jcms.2013.01.002

283. Murali R, Rovit RL. Are peripheral neurectomies of value in the treatment of trigeminal neuralgia? An analysis of new cases and cases involving previous radiofrequency gasserian thermocoagulation. $J \quad$ Neurosurg. 1996;85(3):435-437. doi:10.3171/jns.1996.85.3.0435

284. Mallory GW, Atkinson JL, Stien KJ, Keegan BM, Pollock BE. Outcomes after percutaneous surgery for patients with multiple sclerosis-related trigeminal neuralgia. Neurosurgery. 2012;71 (3):581-586; discussion 586. doi:10.1227/ NEU.0b013e31825e795b 
285. Zadro I, Barun B, Habek M, Brinar VV. Isolated cranial nerve palsies in multiple sclerosis. Clin Neurol Neurosurg. 2008;110 (9):886-888. doi:10.1016/j.clineuro.2008.02.009

286. DMKG Study Group. Misoprostol in the treatment of trigeminal neuralgia associated with multiple sclerosis. J Neurol. 2003;250 (5):542-545. doi:10.1007/s00415-003-1032-1
287. Mohammad-Mohammadi A, Recinos PF, Lee JH, Elson P, Barnett GH. Surgical outcomes of trigeminal neuralgia in patients with multiple sclerosis. Neurosurgery. 2013;73(6):941-950; discussion 950. doi:10.1227/NEU.0000000000000128

\section{Publish your work in this journal}

The Journal of Pain Research is an international, peer reviewed, open access, online journal that welcomes laboratory and clinical findings in the fields of pain research and the prevention and management of pain. Original research, reviews, symposium reports, hypothesis formation and commentaries are all considered for publication. The manuscript

Submit your manuscript here: https://www.dovepress.com/journal-of-pain-research-journal management system is completely online and includes a very quick and fair peer-review system, which is all easy to use. Visit http:// www.dovepress.com/testimonials.php to read real quotes from published authors. 